\title{
Operando Properties of Gas Diffusion Layers: Saturation and Liquid Permeability
}

\author{
Jens Eller, ${ }^{\text {a,*,z } J o ̈ r g ~ R o t h, ~}{ }^{a}$ Federica Marone, ${ }^{\text {b Marco Stampanoni, }}$,,c and Felix N. Büchi ${ }^{\mathrm{a}, *}$ \\ ${ }^{a}$ Electrochemistry Laboratory, Paul Scherrer Institut, CH-5232 Villigen PSI, Switzerland \\ ${ }^{b}$ Swiss Light Source, Paul Scherrer Institut, CH-5232 Villigen PSI, Switzerland \\ ${ }^{c}$ Institute for Biomedical Engineering, University and ETH Zürich, CH-8092 Zürich, Switzerland
}

\begin{abstract}
Polymer electrolyte fuel cells (PEFC) require a sophisticated water management to operate efficiently, especially at high current densities which are needed to reach system cost targets. The description of the complicated two-phase water transport remains a challenge in PEFC models and requires experimental validation on various length scales. In this work, operando X-ray tomographic microscopy (XTM) with scan times of $10 \mathrm{~s}$ was used to depict the liquid water at defined conditions at a technically relevant cell temperature of $80^{\circ} \mathrm{C}$. Cells with Toray TGP-H-060 gas diffusion layer (GDL) with microporous layer (MPL) and different rib width were operated with different feed gas humidifications (under- and oversaturated) and current densities between 0.75 to $3.0 \mathrm{~A} / \mathrm{cm}^{2}$. Based on the quantification of the local and average saturation, the distribution of water cluster size is analyzed. Different categories of the water cluster connectivity are defined and quantified. The analysis is complemented with numerical simulations of the permeability in the liquid phase of the GDL that is correlated to saturation for the different GDL domains. The numerical simulations of the pressure drop of liquid water flow from the catalyst layer toward the gas channels in channel-rib repetition units allows for conclusions on cluster growth mechanisms.

(c) The Author(s) 2016. Published by ECS. This is an open access article distributed under the terms of the Creative Commons Attribution Non-Commercial No Derivatives 4.0 License (CC BY-NC-ND, http://creativecommons.org/licenses/by-nc-nd/4.0/), which permits non-commercial reuse, distribution, and reproduction in any medium, provided the original work is not changed in any way and is properly cited. For permission for commercial reuse, please email: oa@electrochem.org. [DOI: 10.1149/2.0881702jes] All rights reserved.

(cc) BY-NC-ND
\end{abstract}

Manuscript submitted September 6, 2016; revised manuscript received December 9, 2016. Published December 28, 2016. This was Paper 2494 presented at the Honolulu, Hawaii, Meeting of the Society, October 2-7, 2016.

In the past two decades, large developments have lead hydrogen fed polymer electrolyte fuel cell (PEFC) technology to the brink of commercialization, e.g. in the stationary sector with more than 100000 deployments in the Enefarm activity ${ }^{1}$ as well as in the mobile sector where major car manufacturers have presented first commercial vehicles $^{2,3}$ and niche-market commercialization for logistic vehicles. ${ }^{4}$ While for the automotive market also hydrogen infrastructure is a major barrier for widespread application, in both fields of application, cost of the fuel cell system remains the main hindrance for extensive spread of PEFC technology. Cost is closely tied to materials and manufacturing processes, such as more effective electrocatalyst and more durable membrane materials. These developments are underway and have made significant progress. ${ }^{5}$ Cost however is also closely tied to power density of the fuel cell stack. It is obvious that with higher power density less cells or an accordingly smaller cell area with the related reduced material use, is leading to a cost reduction if the high power density materials are of comparable cost.

Automotive fuel cells with state of the art materials and cell structures reach today more than $1 \mathrm{~W} / \mathrm{cm}^{2}$ with current densities up to $3 \mathrm{~A} / \mathrm{cm}^{2}{ }^{2}$. At such high current densities water management becomes more and more important and has to be properly designed on various scales from the system level to nanoscale structures, including all cell components as flow field plates, gas diffusion layers (GDL), the polymer membrane and the catalyst layer (CL). In order to minimize the ohmic losses, the polymer membrane needs to be well humidified, ${ }^{6}$ however at high current densities performance losses from increased gas transport limitations should be avoided. The increase of gas stream saturation along the channel can hardly be avoided without economically unwanted increased gas flow rates and the required size of stack peripherals. Also increasing the cell temperature is not an option since dehumidifying of the membrane has to be avoided. High gas saturation leads to the accumulation of liquid water in the porous gas diffusion layers, especially under the flow field ribs, which results in performance drops due to increased gas transport resistance in particular at the cathode. ${ }^{7-10}$ This effect occurs also at under-saturated conditions when water cannot be transported at sufficient rates anymore in the vapor phase through the GDL and can happen even below

*Electrochemical Society Member.

${ }^{\mathrm{z} E}$-mail: jens.eller@psi.ch
$1 \mathrm{~A} / \mathrm{cm}^{2} \cdot{ }^{9,11-13}$ With respect to conventional flow field structures that use straight gas channels, the most important parameter that controls GDL saturation is the width of the rib between two neighboring channels, which strongly affects the extent of lateral species transport in the GDL.

The structure of the liquid water in the GDL is thus the result of the subtle balance between capillary water transport, heat transport, evaporation and condensation in the complex gradients of humidity and temperature in the porous structure. Many attempts have been made to better understand these phenomena by modeling. ${ }^{14-17}$ The constitutive relation between saturation and liquid permeability is a major input parameter to describe the liquid water transport in the GDL. Different descriptions, mainly derived for soil science applications ${ }^{18-21}$ have been used in macrohomogeneous PEFC two-phase modeling, but experimental evidence for permeability of the liquid water phase in the thin GDL structures, where boundaries and inhomogeneities play an important role is scarce. ${ }^{22}$ So, to date modeling has not been able to capture the complete complexity also due to the difficult description of the boundary conditions, in particular the local variance of the current density on the catalyst layer side, ${ }^{23}$ which is the result of recursive process of local humidity and oxygen transport, and the local temperature on both sides of the GDL.

To date, also on the experimental side no comprehensive description of pore scale water saturation at any technical relevant operating conditions has been given. Neutron and X-ray radiography, provide only averaged saturation information along at least one cell dimension, thus pore scale level processes cannot be depicted precisely with these methods (or only for very small domains ${ }^{24}$ ).

$\mathrm{X}$-ray tomographic microscopy developed during the past years allows insights into pore scale connections and processes (Toyota, ${ }^{2}$ $\mathrm{GM},{ }^{25} \mathrm{Honda}^{26}{ }^{26} \mathrm{PI},{ }^{27,28} \mathrm{ZSW}^{29}$ ) and is particularly suited for imaging the water phase on the level of the pore structure of the GDL. The methodology has been developed for operando measurements and data has been presented for moderate temperature ${ }^{25,26,28,30-32}$ where evaporation/condensation is of low importance or freezing conditions. ${ }^{33}$ However no data has been put forward to date for operating conditions of automotive high power densities at high cell temperatures and current densities, where capillary transport and evaporation/condensation both play important roles. In this study, the liquid water distribution in the cathode GDL is analyzed. Saturation, water cluster size and 
through-plane permeability are determined by XTM in cells operating at $80^{\circ} \mathrm{C}$, with current densities up to $3 \mathrm{~A} / \mathrm{cm}^{2}$, for two different gas humidities and for two flow fields geometries (rib widths).

This work focuses on the analysis of the drainage capabilities of the water saturation in the GDL toward the flow field channels. The key questions are: How much water in liquid phase is present in the GDL at under- and oversaturated conditions? What are the differences between GDL under channel and rib? What is the size of the liquid domains/clusters? Does the liquid water form highly connected networks or stays fragmented into smaller clusters? How many through-plane (TP) connected clusters that provide a hydraulic path toward the flow field channels are there and what is their volumetric share? What is the liquid permeability that these TP-connected water clusters provide and is it high enough to drain water at foreseeable higher current densities? And finally, with respect to modeling efforts of PEFC: What is the correlation between saturation and the permeability of liquid water?

This in-depth analysis of the local saturation and the liquid water transport properties in the GDL provides design criteria for the development of more efficient water removal that will open up the way to higher power density using carbon based materials. A follow-up study will focus on the influence of the water saturation on the gaseous transport in the GDL and on the consequences on cell performance.

\section{Experimental}

A specially designed two-channel $(0.8 \mathrm{~mm}$ width, $0.3 \mathrm{~mm}$ depth, $10 \mathrm{~mm}$ length) PEFC with graphitic flow fields (Sigracet BMA5 from Eisenhuth GmbH, Germany) was used for the XTM experiments (see Figure 1). At least a two-channel design is required to obtain saturation and water distribution data over a channel \& rib repetition unit without boundary bias, as it is the case in a single channel cell (Eller et al. ${ }^{28}$ ). Two different flow field designs, differing only in the rib width $(0.8$ and $1.6 \mathrm{~mm}$ ) were used (see Figure 2). As electrochemical components, catalyst coated membranes (H200) from Solvicore (Hanau, D) based on $50 \mu \mathrm{m}$ dry thickness Nafion membranes were used in combination with Toray TGP-H-060 gas diffusion electrodes (hydrophobized with PTFE, about $10 \%$ ) with a hydrophobic microporous layer (Solvicore H200 cathode GDL/MPL). Between the ribs of the flow field the membrane-electrode assemblies (MEA) were compressed to $450 \mu \mathrm{m}$, corresponding to a compression of the GDLs to about $75 \%$ of their initial thickness. The catalyzed domain of the MEA was $16 \mathrm{~mm}^{2}$ $(4.5 \mathrm{~mm} \times 3.6 \mathrm{~mm})$ and fitted completely into the X-ray beam during the XTM scans. This was necessary to monitor X-ray induced cell performance degradation ${ }^{25,34,35}$. a)

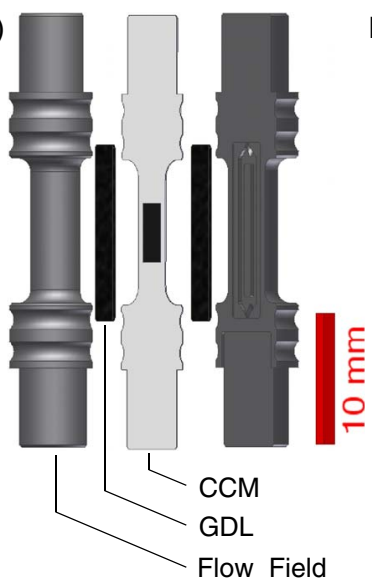

b)

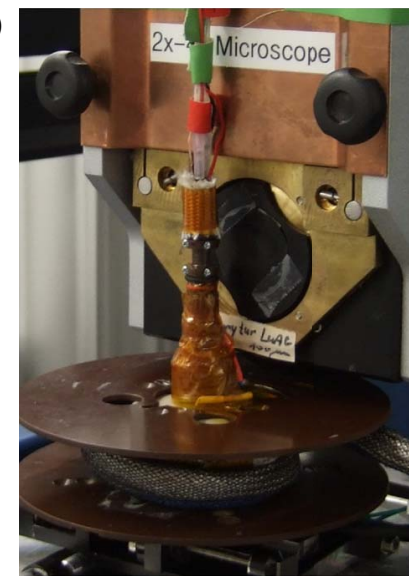

Figure 1. a) Schematics of XTM cell; b) temperature controlled XTM cell with heated socket and heated gas feed tube in front of the TOMCAT zoom objective microscope; exhaust gas lines at cell top are unheated.
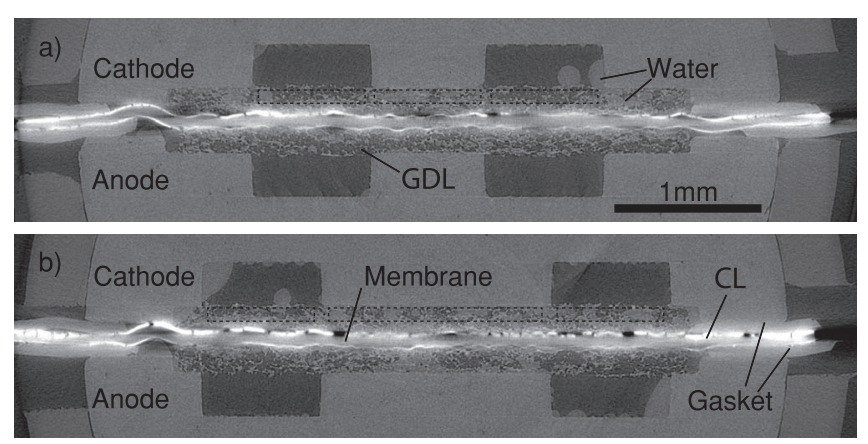

Figure 2. XTM reconstruction of the two channel cell with $0.8 \mathrm{~mm}$ (top) and $1.6 \mathrm{~mm}$ (bottom) wide rib at conditions A03 and A13, respectively; dashed boxes indicate the analyzed cathode GDL domains; 1001 projections of $10 \mathrm{~ms}$ frame time at $13.5 \mathrm{keV}$ with the pco.Dimax camera.

Cells were conditioned at $80^{\circ} \mathrm{C}$ cell temperature before imaging with a $15 \mathrm{~h}$ break in and characterization procedure, that consisted of constant current operation for $5 \mathrm{~h}\left(1 \mathrm{~A} / \mathrm{cm}^{2}, \mathrm{H}_{2} / \mathrm{O}_{2}, 92 \% \mathrm{rH}\right)$ followed by a fine rH-sweep (10 humidity steps between 40 and $104 \% \mathrm{rH}$, $0.75 \mathrm{~A} / \mathrm{cm}^{2}, \mathrm{H}_{2} /$ Air, 30 min hold) and a coarse rH-sweep (3 humidity steps between 65 and $100 \% \mathrm{rH}, 0.75 \mathrm{~A} / \mathrm{cm}^{2}, \mathrm{H}_{2} / \mathrm{Air}, 60$ min hold). Before each $\mathrm{rH}$-sweep the cells were dried by operation at $0.25 \mathrm{~A} / \mathrm{cm}^{2}$, $\mathrm{H}_{2}$ /Air, $40 \% \mathrm{rH}$ for $60 \mathrm{~min}$ and at the end of each $\mathrm{rH}$-step of the coarse rH-sweep a polarization curve (OCV to $1 \mathrm{~A} / \mathrm{cm}^{2}, \mathrm{H}_{2} /$ Air, $5 \mathrm{~s}$ hold) was measured.

At the beamline, the cells were operated at $80^{\circ} \mathrm{C}$ cell temperature at constant current in differential mode with $\mathrm{H}_{2}$ /air or $\mathrm{H}_{2} / \mathrm{O}_{2}(100$ $\mathrm{Nml} / \mathrm{min}$ each; corresponding to dry gas velocities of $\approx 4.5 \mathrm{~m} / \mathrm{s}$ in the gas channels and stoichiometries $>10$ ) humidified at the required dew point. The cells fed with air at the cathode were operated at two feed gas humidities (under- and oversaturated conditions (Ann)) at a fixed current density, whereas the oxygen fed cell was operated at different current densities (On) at fixed (undersaturated) fed gas humidity. All data was obtained at atmospheric gas pressures. Table I gives an overview on the cell parameters for the operation points where XTM images were recorded. The tomographic scans were recorded after 30 min of constant operation at each set point with the sequence of the dew points in descending order and the sequence of current densities in ascending order. At the end of the experiment the cell was dried with a gas feed of $40^{\circ} \mathrm{C}$ dew point for at least 20 minutes and scanned once more to obtain XTM reference data of the dry GDL and flow field structures. The $1 \mathrm{kHz}$ high frequency resistance (HFR) of the cells was monitored with a Tsuruga E3566 AC milliohm meter as a measure for membrane resistivity and thus membrane humidification.

On the rotation stage at the beamline the cells were operated with vertical MEA orientation with the capability to rotate more than $360^{\circ}$. This cell orientation allows for channels extending over the field of view of the X-ray imaging and thus for channel lengths with a well developed flow profile, being representative for large technical cells.

Table I. Cell and set point characteristics of XTM PEFC experiments at $80^{\circ} \mathrm{C}$ cell temperature.

\begin{tabular}{cccccc}
$\begin{array}{c}\text { Experiment } \\
\text { ID }\end{array}$ & $\begin{array}{c}\text { Dew point } \\
{\left[{ }^{\circ} \mathrm{C}\right]}\end{array}$ & $\begin{array}{c}\mathrm{rH} \\
{[\%]}\end{array}$ & $\begin{array}{c}\text { Cathode } \\
\text { Gas }\end{array}$ & $\begin{array}{c}\text { Current Density } \\
{\left[\mathrm{A} / \mathrm{cm}^{2}\right]}\end{array}$ & Rib Size \\
\hline A02 & 74 & 78 & Air & 0.75 & Narrow \\
A03 & 82 & 108 & Air & 0.75 & Narrow \\
A12 & 74 & 78 & Air & 0.75 & Wide \\
A13 & 82 & 108 & Air & 0.75 & Wide \\
O1 & 74 & 78 & Oxygen & 0.75 & Narrow \\
O2 & 74 & 78 & Oxygen & 1.50 & Narrow \\
O3 & 74 & 78 & Oxygen & 2.25 & Narrow \\
O4 & 74 & 78 & Oxygen & 3.00 & Narrow
\end{tabular}



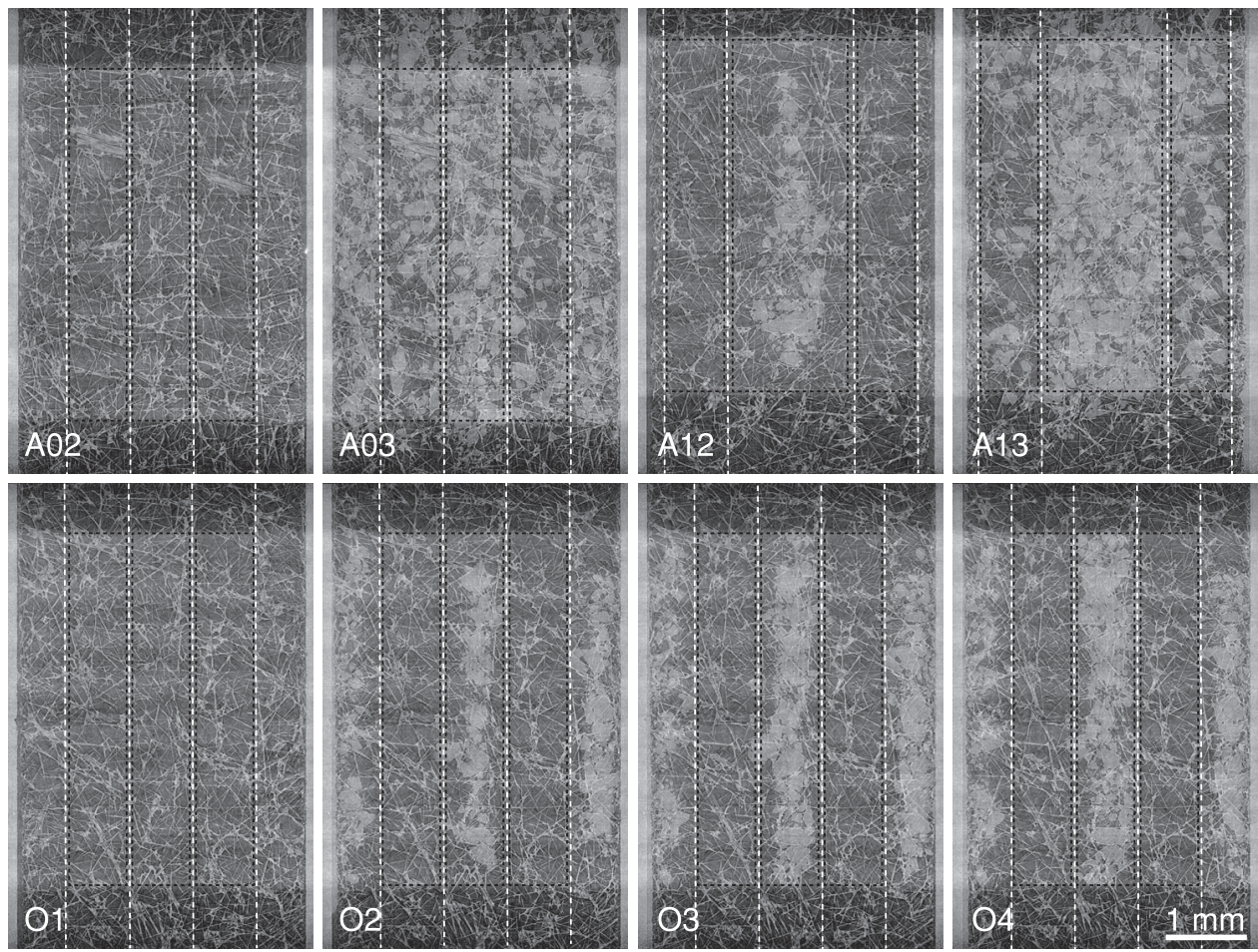

Figure 3. In-plane XTM slices through the cathode GDL for different imaging conditions at a distance of about $45 \mu \mathrm{m}$ from the channel/rib-GDL interface; black dashed boxes indicate the analyzed cathode GDL domains; white dashed lines indicate the edges of the flow field ribs/channels; gas flow direction was from bottom to top; active area of the cells can be identified by a brighter area over the whole slice width (vertically limiting the black dashed boxes).

In order to provide the required operating conditions with dew points of the reactants around $80^{\circ} \mathrm{C}$, the set-up was equipped with in-house designed heated gas tubes which allow the cell to turn with exerting only a minimal torque, to allow for undisturbed imaging.

\section{XTM Imaging and Data Processing}

Imaging.-Operando XTM scans in absorption contrast mode were performed at the TOMCAT beamline of the Swiss Light Source $(\mathrm{SLS})^{36}$ using a fast, CMOS technology based camera (pco.Dimax, Germany), that allows even ultra fast sub-second XTM scans. ${ }^{37}$ The pco.Dimax camera was mounted on a microscope (ELYA solutions, Czech Republic) equipped with a continuous zoom objective providing magnification ranging from $2 \times$ to $3.9 \times$. This combination provides a pixel size of $2.9 \times 2.9 \mu^{2}$, about $5.8 \times 5.8 \mathrm{~mm}^{2}$ field of view and $2.44 \times 10^{-17} \mathrm{~m}^{3}$ voxel size $\left(2.44 \times 10^{-2} \mathrm{pL}\right)$ at the highest magnification and full chip readout $(2016 \times 2016$ pixels $)$. The $\mathrm{Ru} / \mathrm{C}$ multilayer monochromator of the beamline was used and provided a flux of about $(2.1$ to 6$) \times 10^{11}$ photons $/\left(\mathrm{s} \mathrm{mm}^{2}\right)$ at $13.5 \mathrm{keV}$ beam energy with an energy bandwidth of $2 \%$ to $3 \%$, a beam height of about $5.2 \mathrm{~mm}$, and a beam width larger than the actual field of view. The exposure time per projection was $10 \mathrm{~ms}$, so rotating the cell $180^{\circ}$ while taking 1001 radiographic projections led to a total X-ray exposure of $10 \mathrm{~s}$ per scan.

GDL segmentation workflow.-XTM produces 3D gray scale voxel data. The X-ray linear attenuation coefficient in the solid is highest at the catalyst layer which is the brightest material phase in the XTM images (see Figure 2). GDL fibers are second brightest, void is dark and the water has the medium gray scale. After segmentation of the different material phases, quantitative morphological data can be extracted from the XTM data sets. All XTM data sets from Table I have been segmented for void, liquid and solid phase with same thresholding parameters using a workflow similar to the one described in Ref. 28. The GDL solid structure is obtained from a scan of the dry cell, and the liquid phase is obtained by subtracting the dry
XTM data from the wet XTM data of the carefully aligned two data sets.

The catalyzed domain of the MEA is slightly smaller than the beam height. Where catalyst layer is present on the membrane, the gray scale values in the GDL are locally enhanced due to blurring of the strongly absorbing catalyst layer, while in the absence of the catalyst layer XTM slices do not show the brightening of the gray scale values of the GDL (compare Figure 3). This complicates the GDL solid segmentation over the whole channel length. Therefore, and different to Ref. 28, the dry XTM dataset were filtered with an inhouse implementation of the local normalization filter ${ }^{38}$ which allows to remove the inhomogeneous background intensity within the GDL domain. The filter was applied in 2D for the in-plane (IP) direction to remove the CL patterns and in through-plane direction to remove the gradient of the gray levels from the CL toward the flow field. The latter step can be interpreted as a generalization of the adaptation of the solid threshold in through-plane direction in the initial workflow of Ref. 28.

Quantification of liquid water.-The quantification of the liquid saturation in all analysis was limited to the top $90 \mu \mathrm{m}$ of the cathode GDL to avoid influences from the MPL domain, since XTM cannot resolve liquid water in the MPL nano-pores and the difficulties in MPL segmentation that cannot be overcome with the local normalization for this thin and inhomogeneous type of MPL. The analyzed GDL domains were furthermore limited ${ }^{\mathrm{d}}$ to the domains with catalyst present on the membrane (brighter sections in the IP-slices of Figure 3) and subdivided into cuboid domains representing the GDL under the rib and the channels, as shown in Fig. 2 and Fig. 3. The subdomain cuboids were located centered under channels and ribs with dimensions of $725 \mu \mathrm{m} \times 90 \mu \mathrm{m} \times 4439 \mu \mathrm{m}(250 \times 31 \times 1531$ voxel) under the channels and the small ribs, but $1450 \mu \mathrm{m} \times 90 \mu \mathrm{m}$

${ }^{\mathrm{d}}$ The location of the analyzed domain was slightly readjusted compared to Refs. 39 , 40 , which leads to some deviations of the saturation values. General trends between the different samples/conditions remain unchanged. 
$\times 4439 \mu \mathrm{m}(500 \times 31 \times 1531$ voxel $)$ under the wider ribs of A12 and A13 excluding the domains directly under the edges of the flow field ribs from the analysis. The resulting subdomain volumes are about $0.3 \mathrm{~mm}^{3}$, respectively $0.6 \mathrm{~mm}^{3}$, and the in-plane cross-section of the subdomains are with $3.2 \mathrm{~mm}^{2}$, respectively and $6.4 \mathrm{~mm}^{2}$, clearly above the limits of a representative equivalent area (REA) of Toray TGP-H-060 GDLs as shown by Roth et al. ${ }^{41}$.

The water clusters of a sample volume $V$ were identified using the bwlabeln routine of the image processing toolbox of Matlab ${ }^{42} \mathrm{e}$ and their bounding box was calculated. All 26 neighboring voxels of the center of a cube with 27 voxels were accepted as connection of two voxels. Based on the bounding box information, the water clusters within the analyzed GDL domain were assigned to different connection type cluster categories. In order to avoid wrong classifications, the assignment step was implemented before cropping channel and rib subdomains.

Permeability calculations.-The permeability $\kappa$ (see Eq. 1) is a physics based measure of pore space connectivity and convective transmissibility for low Reynolds numbers fluid flows $(R e \ll 1)$ that can be be defined through Darcy's law

$$
\kappa_{a b}=\frac{\mu u_{b, \text { mean }}}{|\partial P / \partial a|}
$$

where $\mu$ is the dynamic viscosity, $u_{b \text {, mean }}$ is the volumetric mean velocity inside the sample in the direction $b=\left\{x_{b}, y_{b}, z_{b}\right\}$, and $\partial P / \partial a$ is the pressure gradient in direction $a=\left\{x_{a}, y_{a}, z_{a}\right\}$. In this work, throughplane permeability of the porous media has been calculated with the LIR-Stokes solver of the FlowDict module of GeoDict (Math2Market $\mathrm{GmbH}$, Germany) for the liquid water domain $\left(\kappa_{l}\right)$ and for the void of the dry structure as reference $(\kappa)$. Based on the two values the relative liquid permeability $\kappa_{r l}=\kappa_{l} / \kappa$ can be calculated. The calculations used periodic boundary conditions at the inflow and outflow boundaries of the sample with an added void in-flow region of 20 voxel thickness and a fixed pressure difference (20 Pa, fluid: air), but symmetric boundary conditions at other sample boundary areas. For calculating the pressure drop within the liquid phase, a flow rate boundary condition of $5.76 \times 10^{-6} \mathrm{l} /\left(\mathrm{min} \mathrm{cm}^{2}\right)$ per $1 \mathrm{~A} / \mathrm{cm}^{2}$ was applied for liquid water at $80^{\circ} \mathrm{C}$ (density of $971.8 \mathrm{~kg} / \mathrm{m}^{3}$, viscosity of $3.9 \times 10^{-4} \mathrm{~kg} / \mathrm{ms}$ ).

\section{Results}

Electrochemical performance.-For the cells and operating conditions with air at the cathode (Ann), the influence of the feed gas humidification (under- and oversaturated, $78 \%$ and $108 \%$, respectively) and the width of the rib on cell voltage and water distribution was studied. The undersaturated conditions were chosen such that they represent the optimal feed gas humidity providing the maximum cell voltage at a current density of $0.75 \mathrm{~A} / \mathrm{cm}^{2}$. The cell voltage for air fed cells is shown for a broad dew point variation in Figure 4a. A maximum of the cell performance is observed at dew points between 74 and $76^{\circ} \mathrm{C}$ (corresponding to 78 to $85 \% \mathrm{rH}$, respectively). While the decreasing cell performance at lower dew points can be explained by lower membrane conductivity (higher HFR values), the decreasing cell performance at higher dew points are not a result from membrane resistance changes. The HFR is decreasing from values around $75 \mathrm{mOhm} \mathrm{cm}^{2}$ for optimal humidity

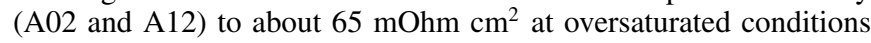
(A03 and A13). Performance loss must therefore be due to mass transport limitations at fully humidified conditions. At the beamline the cells performed slightly better at undersaturated conditions (A02 and A12) than during performance-characterization, whereas cell voltages at the oversaturated conditions (A03 and A13) agree well.

Figure $4 \mathrm{~b}$ shows the polarization curve characteristics of the cells operated with $\mathrm{H}_{2}$ /air and $\mathrm{H}_{2}$ /oxygen at $80^{\circ} \mathrm{C}$ cell temperature with the
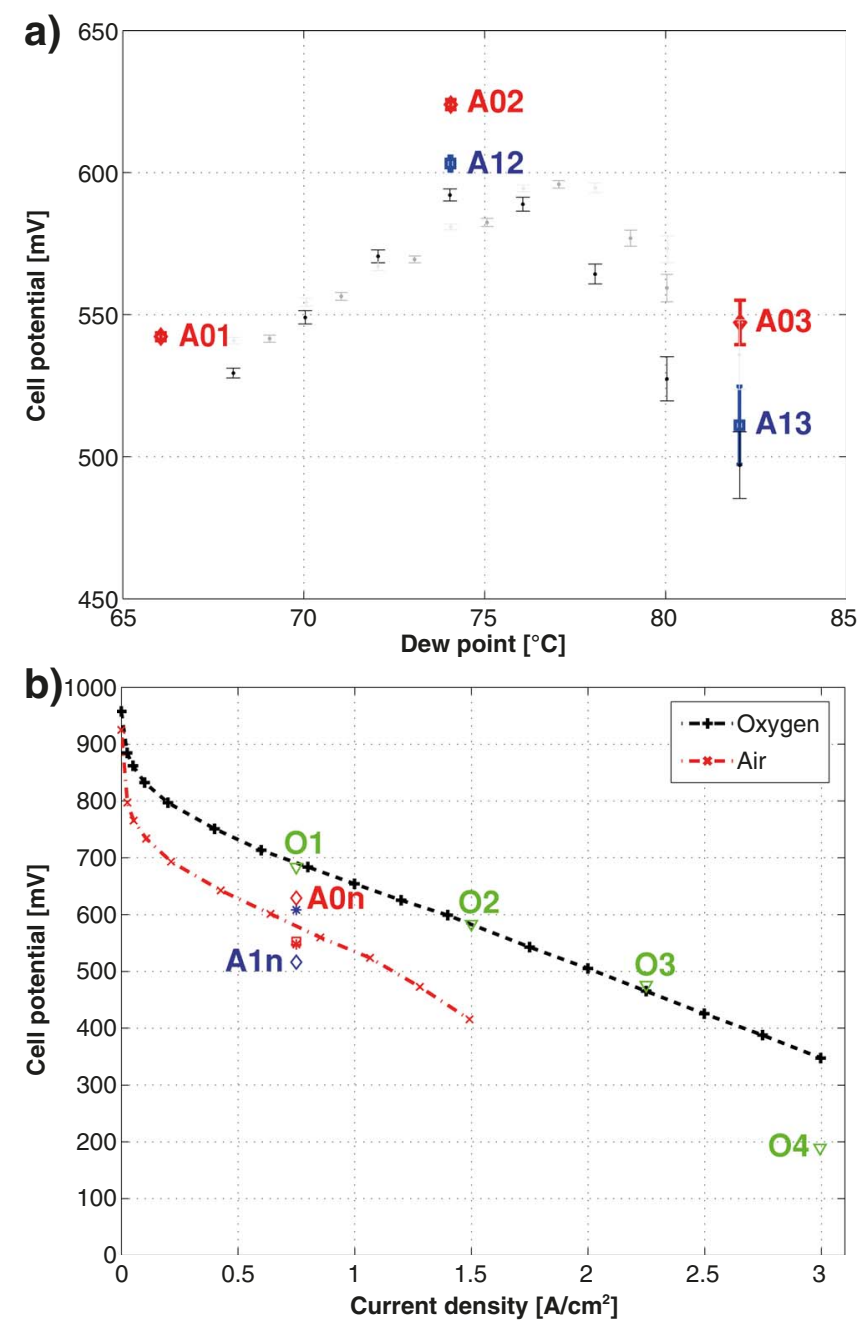

Figure 4. a) Cell voltage for $\mathrm{H} 2 /$ air operation at $0.75 \mathrm{~A} / \mathrm{cm}^{2}$ as function of gas dew point; b) current voltage curves for operation with air and oxygen (both for narrow rib) at dew point of $76^{\circ} \mathrm{C}$; cell temperature always $80^{\circ} \mathrm{C}$; labels refer to conditions imaged by XTM; gray/black error bars indicate precharacterization results for different cells during rH-variation; condition A01 is shown in accordance with Eller et al., ${ }^{39}$ but not further discussed in this work.

undersaturated feed gas humidity ( $\mathrm{rH}$ of $78 \%$ ) and atmospheric gas pressures. At this dewpoint the onset of mass transport losses can be observed above $1 \mathrm{~A} / \mathrm{cm}^{2}$ for air operation, whereas no mass transport limitation becomes obvious up to $3 \mathrm{~A} / \mathrm{cm}^{2}$ for oxygen operation in the differential mode. In order to access the water saturation for a large range of current densities, pure oxygen feed gas at the cathode was selected for imaging. The water phase was imaged at four different current densities between 0.75 and $3.0 \mathrm{~A} / \mathrm{cm}^{2}$ at the undersaturated feed gas settings (On).

The cell voltage of all $\mathrm{H}_{2}$ /air conditions and the $\mathrm{H}_{2}$ /oxygen conditions $\mathrm{O} 1$ - $\mathrm{O} 3$ match well with the values obtained during precharacterization. Significant radiation induced bias of the cell voltage was only observed at condition $\mathrm{O} 4$. This cell was already exposed to the synchrotron radiation for $30 \mathrm{~s}$ during the XTM scans of conditions O1-O3, whereas the two $\mathrm{H}_{2}$ /air cells of the humidity variation were irradiated only for $10 \mathrm{~s}$ before condition An2. This is consistent with previous X-ray exposure studies, ${ }^{35}$ where a significant voltage bias was observed after $30 \mathrm{~s}$ irradiation at same photon energy and flux at TOMCAT at $80^{\circ} \mathrm{C}$ cell temperature. Since the cells were operated with constant current set-points, the water production rate at condition $\mathrm{O} 4$ was not affected. The additional overpotential of $150 \mathrm{mV}$ leads 

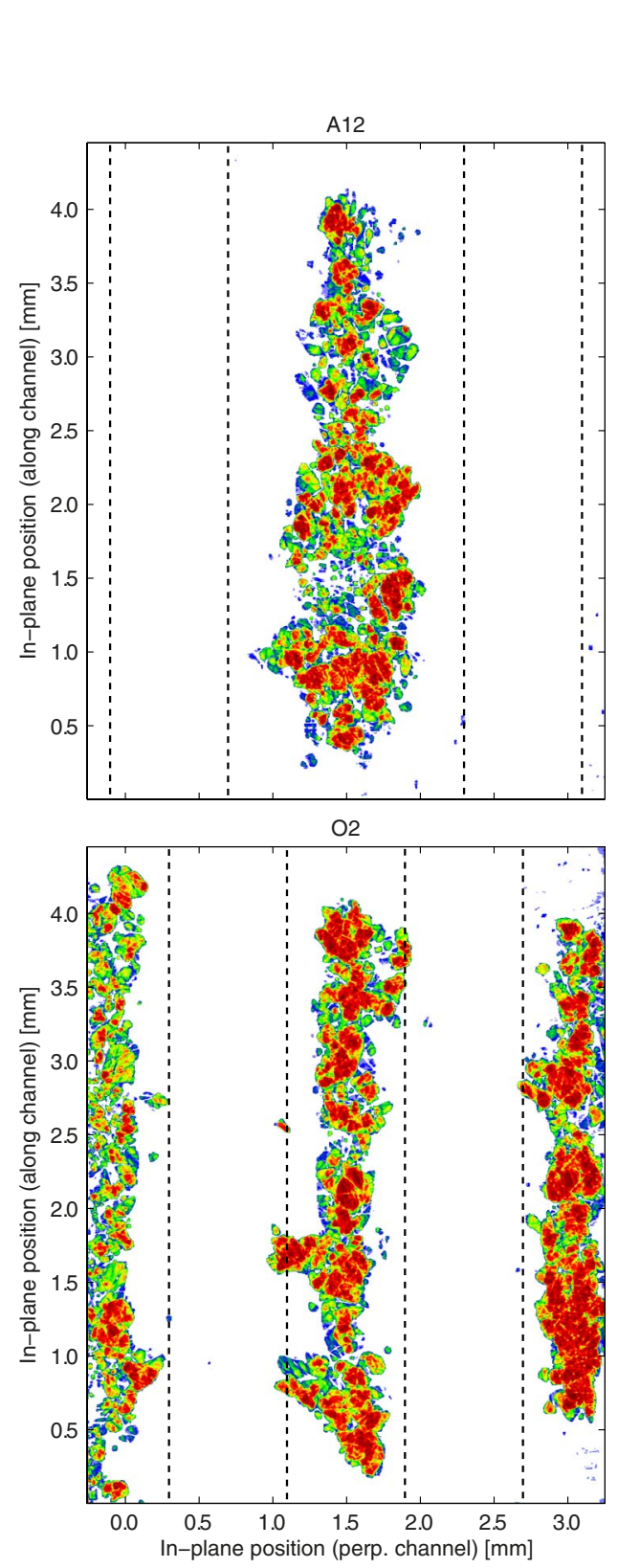
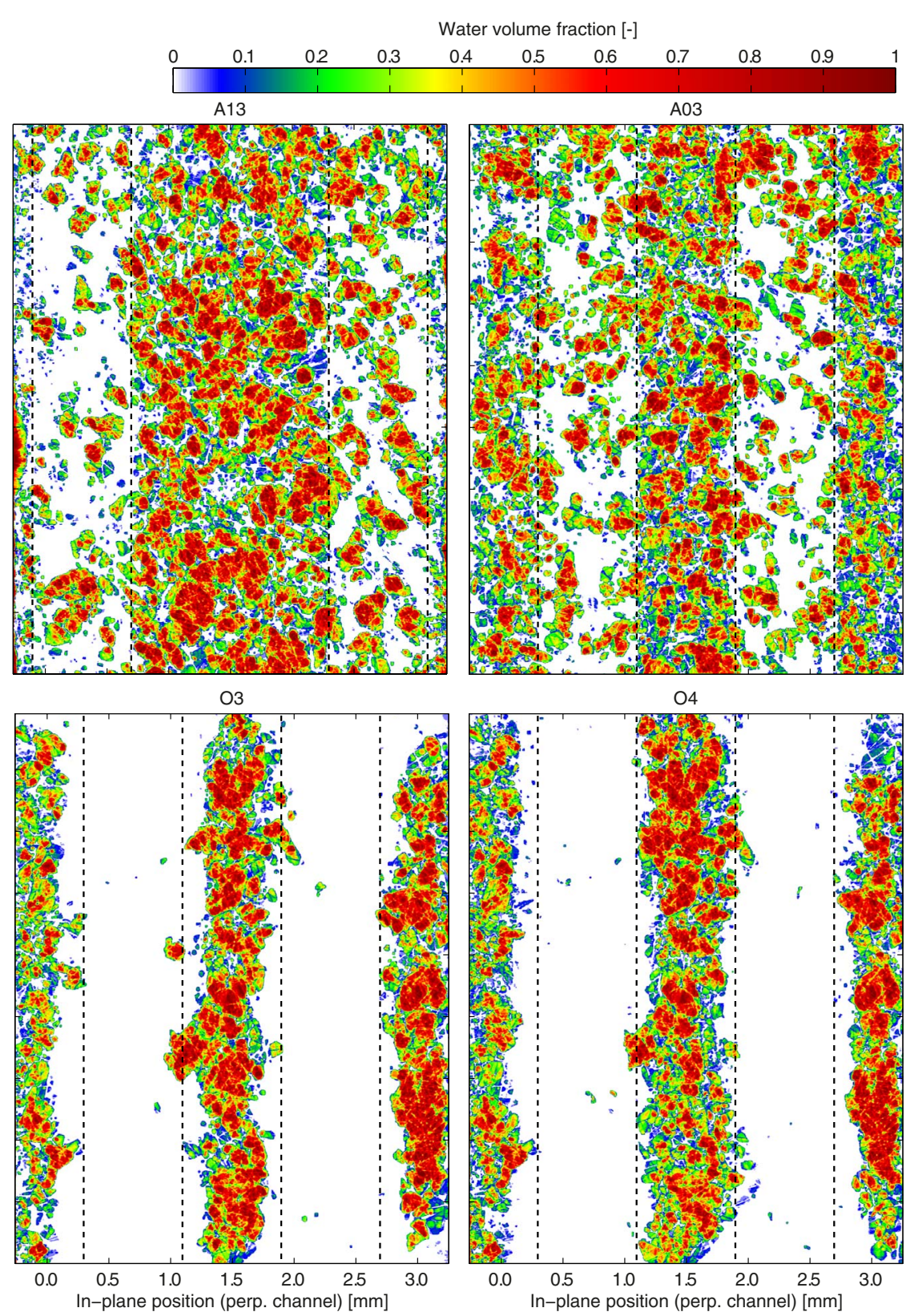

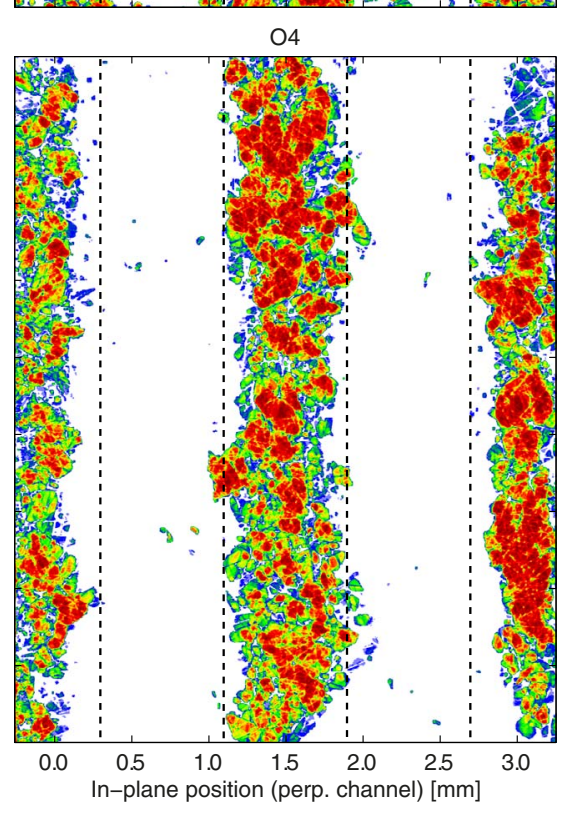

Figure 5. 2D projection of the liquid water volume fraction in the analyzed $90 \mu \mathrm{m}$ thick GDL domain in through-plane direction; black dashed lines indicate the edges of the flow field ribs/channels.

to an increase of $20 \%$ of the cell's heat production (about $3 \mathrm{~W} / \mathrm{cm}^{2}$ instead of $2.5 \mathrm{~W} / \mathrm{cm}^{2}$ ). The influence on liquid saturation at $\mathrm{O} 4$ can't be quantified but is expected to be non-dominant.

Quantification of the liquid saturation.-In Figure 3 in-plane (IP) slices through the cathode GDL for the different operating conditions and rib widths are shown. These single slices (in a plane about $45 \mu \mathrm{m}$ from the channel/rib-GDL interface) illustrate the prominent effect of gas feed humidity, rib dimensions and current density on the saturation of the cathode GDL. At the highest gas feed humidification conditions A03 and A13 liquid water is found in the GDL both under channel and rib. At optimal gas feed humidification liquid water is only present in the GDL of the wide rib cell (A12) but not in the narrow rib cell (A02 and O1). Only for the oversaturated conditions of A03 and A13 considerable amounts of liquid water can be observed outside the catalyst containing MEA area, especially in the downstream direction of the gas flow. In case of the current density variations $\mathrm{O} 1$ to $\mathrm{O} 4$ $\left(0.75 ; 1.5 ; 2.25\right.$ and $\left.3.0 \mathrm{~A} / \mathrm{cm}^{2}\right)$ the saturation is clearly increasing with current density, predominantly but not exclusively in the rib area. Furthermore, the liquid saturation under the ribs of the high current density scans $(\mathrm{O} 2-\mathrm{O} 4)$ seems to be more dense and less fragmented than the rather clustered saturations of $\mathrm{A} 03$ and $\mathrm{A} 13$.

This observation is confirmed by the through-plane projection of the water voxels in the analyzed GDL domain (see Figure 5). For conditions $\mathrm{O} 2$ and $\mathrm{O} 3$ a dense water accumulation under the center of the ribs is found, where only a few branches of liquid water provide paths to the channel area. As the saturated area becomes wider from $\mathrm{O} 2$ to $\mathrm{O} 4$, a more homogeneous front toward the channel area is formed. In the channel domains, a significant saturation can be found only at the high $\mathrm{rH}$ conditions A03 and A13. There, covering about $40 \%$ of the GDL area, the saturation is more fragmented than under the ribs with about $80 \%$ coverage. 

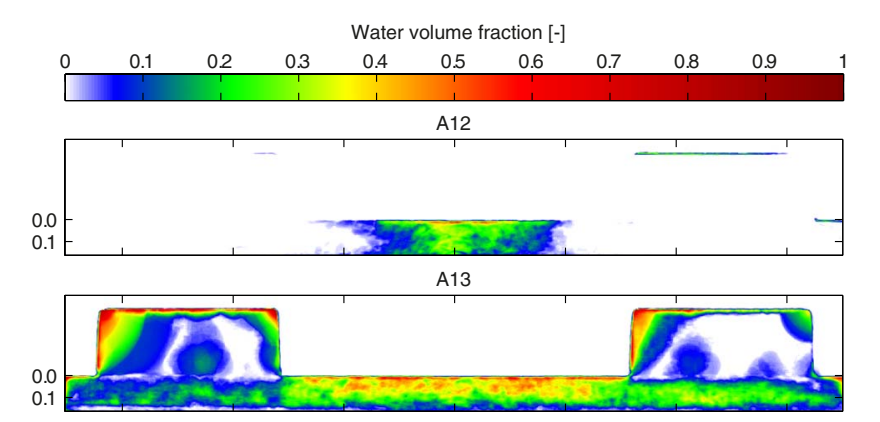

A03

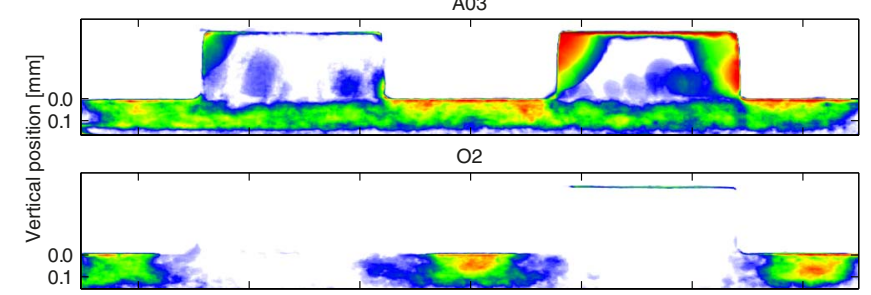

$\mathrm{O} 3$
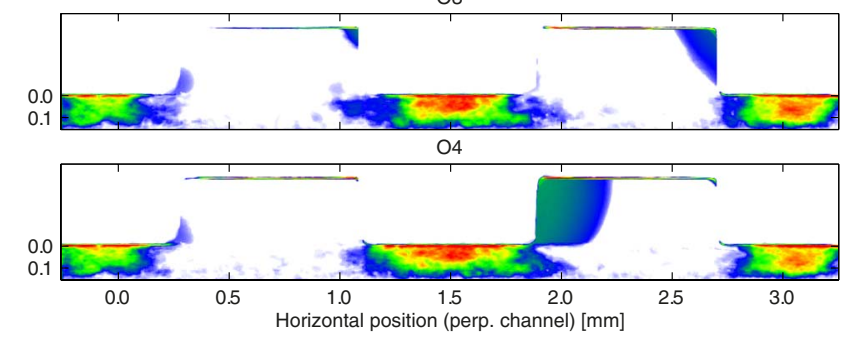

Figure 6. $2 \mathrm{D}$ projection of the liquid water volume fraction along the flow channel direction; the GDL domains are cropped above the MPL/CL interface.

In the GDL rib and channel domains many locations with water volume fractions of $70 \%$ and higher can be identified. These locations likely provide a liquid connection through the entire thickness of the MPL-free domain, allowing for liquid transport between CL and channel or rib.

The projections of the water volume fraction along the channel direction (see Figure 6) confirms the high accumulation of liquid water under the ribs of the oversaturated conditions A03 and A13 and also for the high current density conditions $\mathrm{O} 2$ to $\mathrm{O} 4$ from a different viewing angle. While the high $\mathrm{rH}$ conditions show widespread high water volume fractions above $40 \%$ under the ribs, the high current density conditions show a more centered distribution with volume fractions of up to $50 \%$ under the ribs center and only about 10 to $20 \%$ in the outer rib domains. The cumulonimbus like pattern under the wide rib of the undersaturated condition A12 suggests that there are liquid TP connection paths possible even at a $\mathrm{rH}$ of only $78 \%$. As expected from the through-plane projections, only the channel GDL domains of the oversaturated conditions show water volume fractions of up to $30 \%$, whereas for conditions $\mathrm{O} 2-\mathrm{O} 4$ a signature of the tails of the rib saturation into the channel GDL is observed at levels of up to around $5 \%$.

In the domain of the flow channels of Figure 6 faint water droplets on the GDL surface (oversaturated conditions A03 and A13) and the contour of plug flow along the flow field walls (A03 and A13 and high current density conditions $\mathrm{O} 2-\mathrm{O} 4)$ are observed.

For better comparison of the in-plane and through-plane projections, the water volume fraction, rather than the saturation is used in Figures 5 and 6. Saturation data projected (or averaged) along the channel and the investigated GDL thickness is given in Figure 7. As discussed already above, it can clearly be seen that the increasing gas humidity leads to an increase of the liquid saturation in the entire GDL including a significant saturation also in the channel area (Figures 7 top and middle), whereas higher current densities mostly increase the
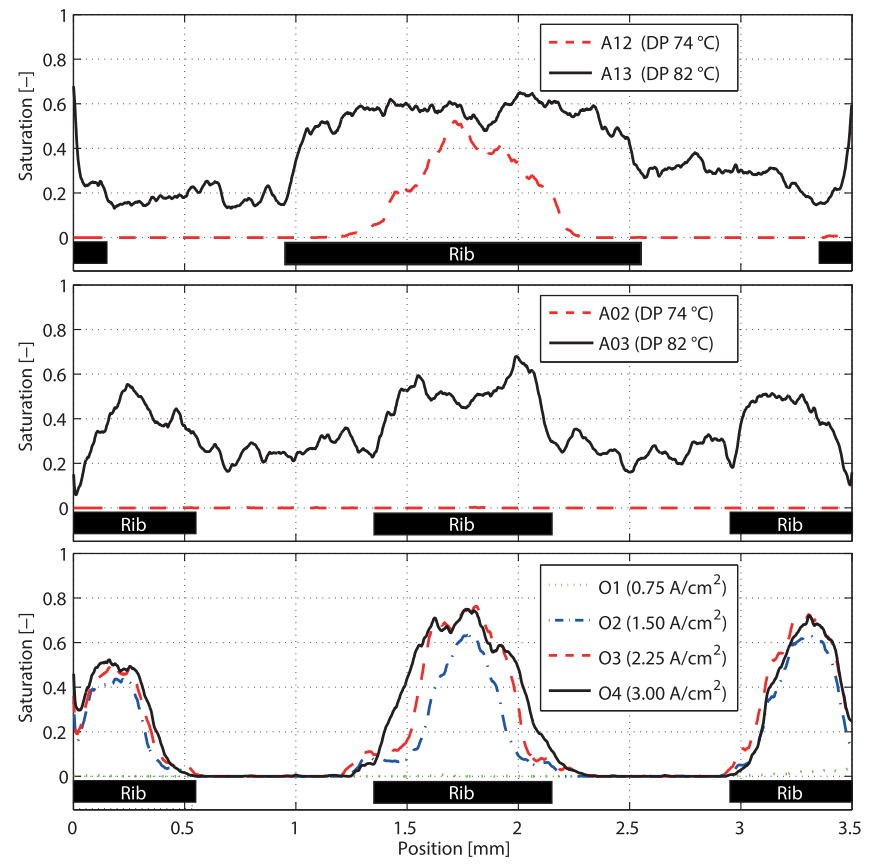

Figure 7. Saturation profiles of cathode GDL across the cell width averaged along the active area $(4.5 \mathrm{~mm})$ and for a height of $90 \mu \mathrm{m}$ of the GDL from the channel/rib-GDL interface.

saturation in the rib area (O2-O4, Figure 7 bottom). The maximum saturation did not rise significantly from $2.25 \mathrm{~A} / \mathrm{cm}^{2}(\mathrm{O} 3)$ to $3.0 \mathrm{~A} / \mathrm{cm}^{2}$ $(\mathrm{O} 4)$, but the liquid volume under the rib increased laterally. The small stripe of channel GDL domain with an average saturation not exceeding $10 \%$, seems to be necessary to drain the liquid water from the rib domain into the gas channels at the higher current densities.

Comparing the oversaturated conditions (A03 and A13) with the highest current density condition (O4) spatial differences of the saturation under the rib are again obvious, though the high mean saturation values above $50 \%$ are comparable. The profiles of A03 and A13 are rather homogeneous and high values are found close to the edges of the ribs, but a saturation of 0.6 is rarely exceeded. For O4, the saturation reaches even 0.75 but the profile is still bell shaped, similarly to $\mathrm{O} 2$ and $\mathrm{O} 3$, with lower values toward the edges of the ribs, where undersaturated feed gas humidities seem to promote water removal by evaporation. This is not possible at the oversaturated conditions of A03 and A13 with average channel GDL saturation of about $25 \%$ resulting in high GDL saturations at the rib edges.

Table II provides a summary of the average saturations and porosities of the channel and rib GDL domains for the different conditions an rib widths.

Quantification of water clusters.-The projection of water clusters in the through-plane direction shown in Figure 5 reveals the locations of high local saturation. But it fails to conclude which water accumulation provides a hydraulic connection from the CL/MPL interface to the channel, especially under the ribs, where drainage of liquid water into the channel requires hydraulic connections over some tens of pores in-plane direction. Labeling the individual water clusters, this question can be addressed both in through-plane and in in-plane direction. The distribution of cluster volumes, cluster numbers and cluster density is therefore analyzed and discussed for GDL domains with an average saturation larger than $1 \%$.

Figure 8 shows a 3D visualization of the liquid water, where the 10 largest clusters of each domain are colored differently than the smaller clusters. Under the ribs, the majority of the saturation seems to be collected by at maximum 5 clusters for all conditions. Conditions O3 and $\mathrm{O} 4$ are even dominated by a single cluster that spans over the entire field of view in the along-the-channel direction. For the oversaturated 


\begin{tabular}{|c|c|c|c|c|}
\hline Experiment & \multicolumn{2}{|c|}{ Porosity [\%] } & \multicolumn{2}{|c|}{ Saturation [\%] } \\
\hline ID & Channel & Rib & Channel & Rib \\
\hline A02 & 65.1 & 64.3 & 0.1 & 0.1 \\
\hline A03 & $-\|-$ & $-\|-$ & 26.5 & 51.6 \\
\hline A12 & 62.5 & 64.4 & 0.0 & 17.8 \\
\hline A13 & $-\|-$ & $-\|-$ & 24.0 & 55.2 \\
\hline $\mathrm{O} 1$ & 64.4 & 66.6 & 0.0 & 0.0 \\
\hline $\mathrm{O} 2$ & $-\|-$ & $-\|-$ & 0.3 & 28.6 \\
\hline $\mathrm{O} 3$ & $-\|-$ & $-\|-$ & 0.7 & 43.7 \\
\hline $\mathrm{O} 4$ & $-\|-$ & $-\|-$ & 0.5 & 51.6 \\
\hline
\end{tabular}

conditions the largest clusters under the ribs seem even to expand into the channel GDL domains. There, the ten largest clusters are of similar size and cover only about $50 \%$ of the water volume.

In order to further quantify the cluster volume distributions, cumulative plots of water volumes and cluster numbers versus cluster volume on a logarithmic scale are presented in Figure 9. The volume distribution of the individual water clusters in the different domains spans over 5 to 6 orders of magnitude from few pL up to almost $140 \mathrm{~nL}$ (about one seventh of a millimeter cube). The visual impression of Figure 8 that the water volume is dominated by few clusters is confirmed as under the ribs (Figure 9a and 9b), about $90 \%$ of the water is found in at the most 4 of the largest clusters.

For the wide rib and oversaturated condition A13, only the largest cluster contains about $66 \%$ of the total water volume. For conditions $\mathrm{O} 3$ and $\mathrm{O} 4$ even more than $95 \%$ of the total water volume are connected. The largest cluster at $3.0 \mathrm{~A} / \mathrm{cm}^{2}$ (O4) has $94 \mathrm{~nL}$, but it is still smaller than the largest cluster of A13 with a volume of $137 \mathrm{~nL}$. Table III lists the volume of the largest cluster for each condition/domain. On the other end of the cluster size distribution, the smaller $90 \%$ of the clusters under the ribs contain less than $5 \%$ of the total water volume.

When looking at the distributions for the channel domains (Figure $9 c)$ it is seen that the water volume is less dominated by very few large clusters and the maximum cluster size is limited to about $10 \mathrm{~nL}$. Since the water clusters can drain directly into the channel, they remain therefore isolated and do not grow above $10 \mathrm{~nL}$ threshold. This is in contrast to the rib domains, where the GDL-rib interface acts as a barrier that forces the TP-transport clusters to join either by capillary pressure to in-plane growth or by condensation due to the slightly lower temperatures at the GDL-rib interface. The smaller $90 \%$ of the clusters in the channel GDL domains contain about $10 \%$ of the total water volume, as the D90 value of the size distribution is shifted to an order of magnitude larger cluster sizes compared to the GDL rib domains.

When analyzing the slope of the cumulative cluster number plots, around 85 to $95 \%$ the highest negative curvature is observed. The bending of the curve is at cluster sizes of $20-60 \mathrm{pL}$. This slope change is rather discrete for the channels and more smooth for the rib domains. The flattening of the cluster number distribution means that beyond this bending point there are less clusters per decade of volume. This characteristic volume can be correlated to pore sizes. If a cluster overcomes the barrier posed by the throats of its initial pore, it will probably continue to grow further as its growing mechanism will allow him to overcome also a similar sized throat of the next pore. This would mean that there should be fewer clusters with a volume of two pores than clusters with a volume less than a pore and a lower slope of cluster number distribution beyond the single pore volume can be expected. In general, it is difficult to geometrically define a pore shape for the random and highly porous GDL materials. Depending on the pore shape assumptions, the average pore volume for Toray type GDLs spans between $10 \mathrm{pL}$, assuming cylindrical pore cross sections or spherical pores with a diameter of $20-30 \mu \mathrm{m},{ }^{32,43}$ and $75 \mathrm{pL}$ if one considers the anisotropy of pore dimensions ${ }^{44}$ by somewhat cuboid pores $(50 \mu \mathrm{m} \times 50 \mu \mathrm{m} \times 30 \mu \mathrm{m})$. Consequently, the volume of $20-60 \mathrm{pL}$ at the curve bending can be understood as an indicator for average pore size.

The through-plane (TP) size of clusters is important as particularly those linking the CL/MPL interface with the channel or rib interface are of high relevance for the liquid water transport. The smallest water clusters, that span over the channel GDL domain in throughplane direction have a volume of about 0.2 to $0.5 \mathrm{~nL}$, as can be seen in Figure 10 exemplarily for condition A03's left channel GDL, where TP-size is plotted over the cluster volume. At the same time some water clusters of similar or larger volume exist, that do not expand over the full GDL thickness or maybe just over $50 \%$ of the analyzed GDL TP-dimension. It is therefore difficult to decide if a water cluster provides a TP-percolation path based on the cluster volume.
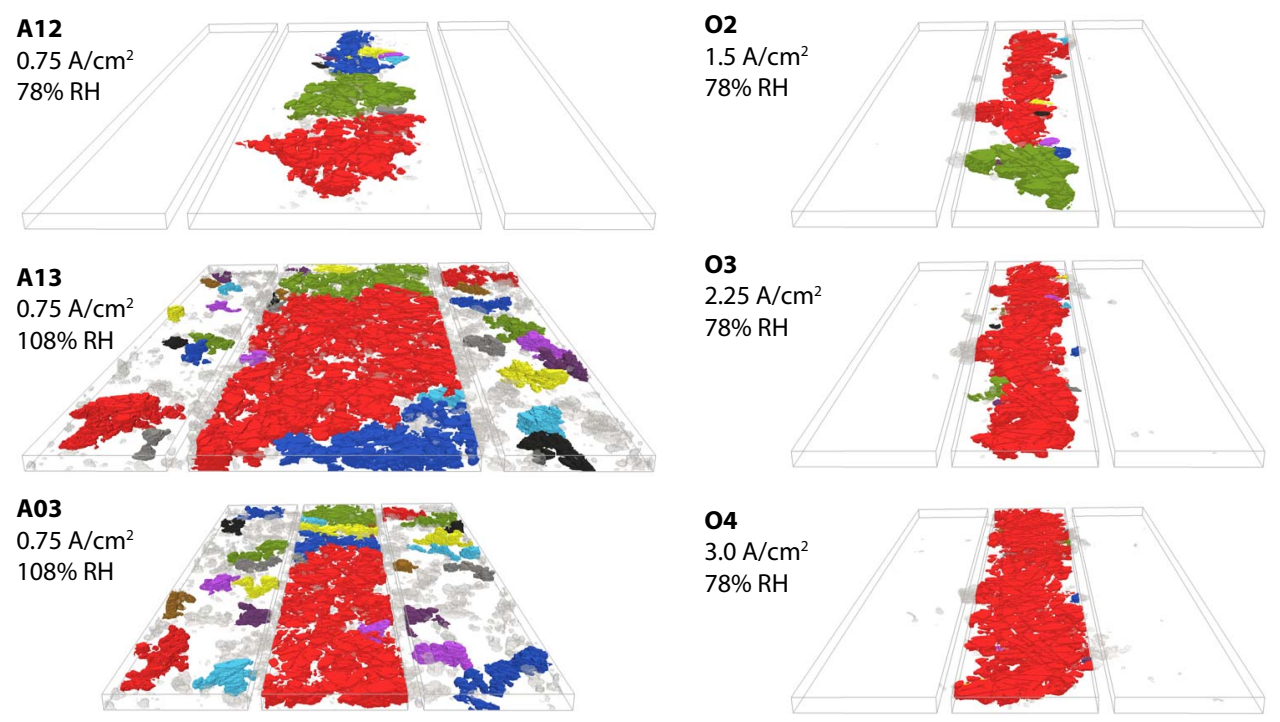

Figure 8. 3D rendering water saturation of the individual channel and rib domains for all conditions with water saturation above $1 \%$. The 10 largest clusters are colored individually. 

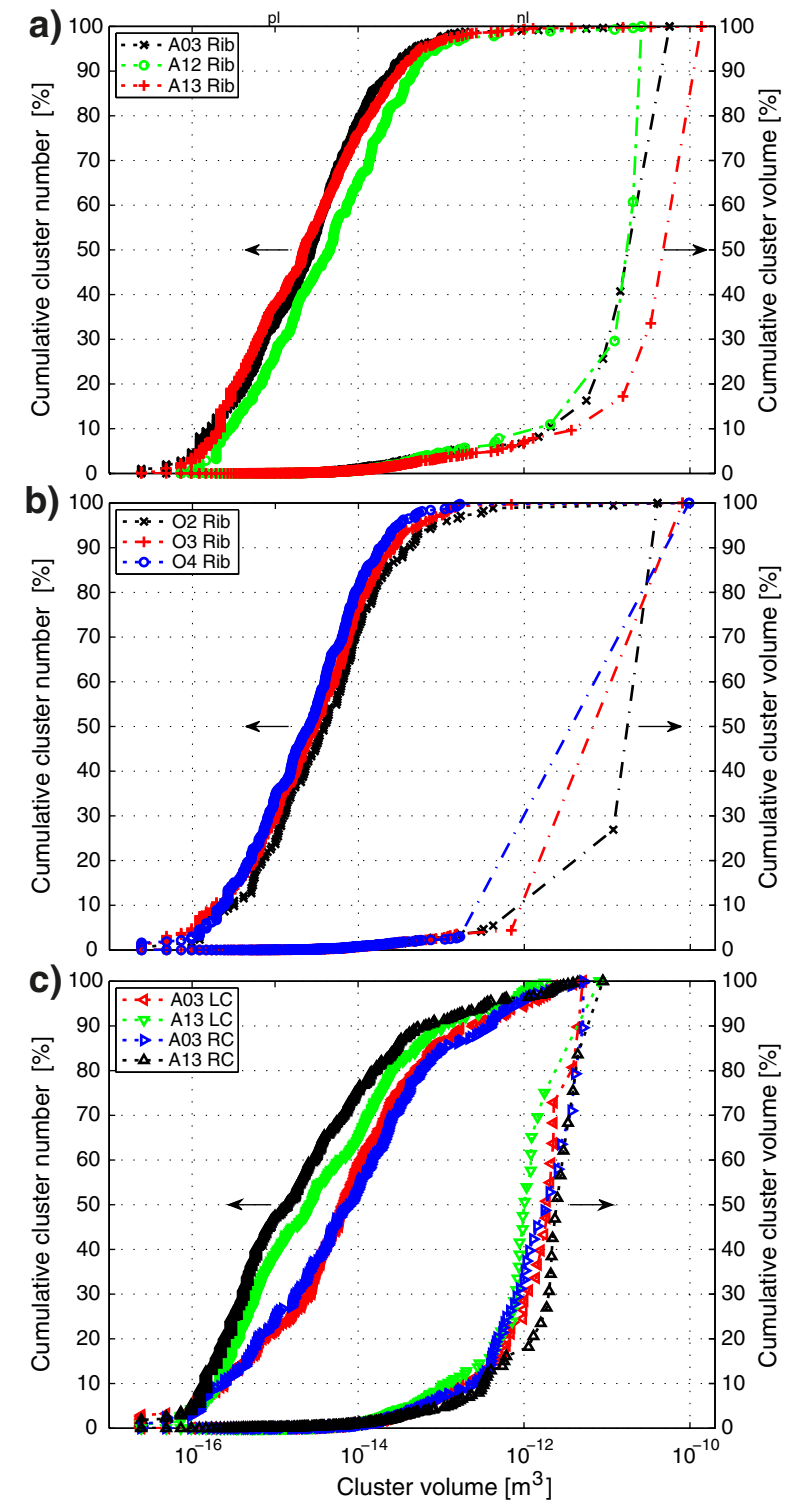

Figure 9. a)-c) Cumulative representation of number of clusters and cluster volume plotted against cluster volume; comparison of a) rib domains of air conditions, b) rib domains of oxygen conditions and c) channel domains of air conditions. Clusters below $0.1 \mathrm{pL}$ ( 4 voxels) can be regarded as remaining noise in the segmentation.

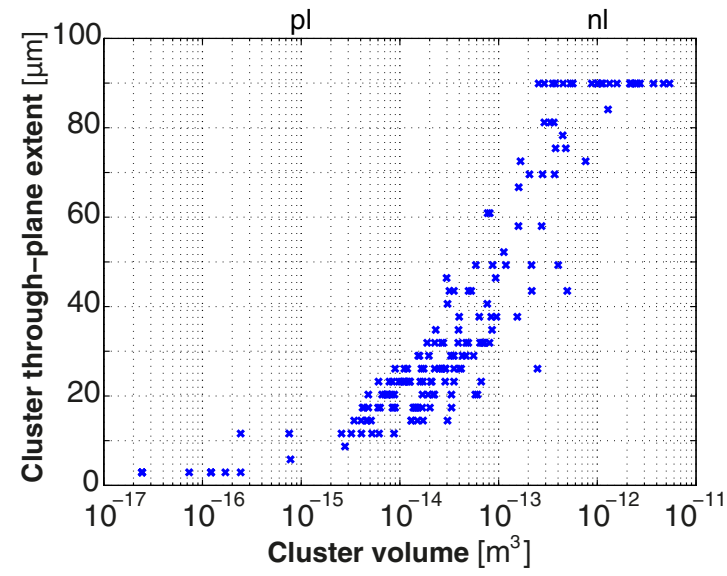

Figure 10. Through-plane extent of water clusters in $90 \mu \mathrm{m}$ thick GDL domain under left channel of A03.

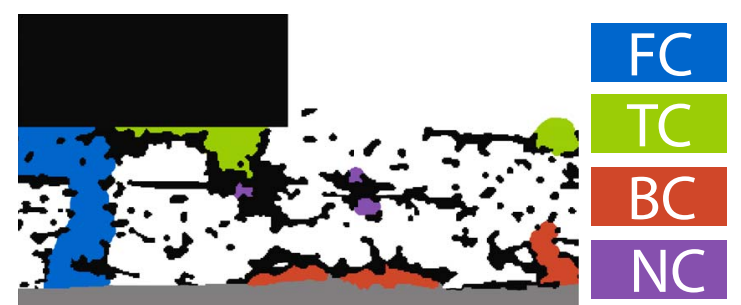

Figure 11. Sketch of the different cluster types that can be found in the GDL domain; blue: full connected water clusters (FC); green: top connected (TC); red: bottom connected (BC); purple: non connected (NC); rib domain and GDL fibers are shown in black, catalyst layer and membrane are shown in gray.

Classification of water clusters.-In order tho determine which accumulation of liquid water is involved in liquid transport through the GDL toward the channel, TP-connectivity is a major criteria, as outlined above. As shown in Figure 10, cluster volume is a prerequisite, but it is not a sufficient measure for TP-connectivity. Consequently, the individual water clusters have been classified into different clusters categories. It is distinguished between full connected (FC) water clusters, that provide a percolation path in TP-direction from bottom to the top of the GDL, bottom connected (BC) and top connected (TC) water clusters that are only connected to the top or the bottom of the GDL domain, respectively, and isolated, non-connected (NC) water clusters (see Figure 11 for a schematic visualization). Results of the analysis are given in Table IV only for domains with average liquid saturation above $1 \%$ to avoid the discussion of artifacts and non significant fluctuations.

Table III. Volume and bounding box dimensions of largest cluster $\left(l_{\mathrm{Cl}}\right)$ in each cathode GDL domain $\left(l_{\mathrm{BB}}\right)$ with a saturation $>1 \%$. For the channels the values of the largest cluster of the two channel domains is given.

Bounding box dimensions

\begin{tabular}{|c|c|c|c|c|c|c|c|c|}
\hline & & \multirow{4}{*}{$\begin{array}{c}\text { Volume } \\
\text { V } \\
{[\mathrm{nl}]}\end{array}$} & \multirow{2}{*}{\multicolumn{2}{|c|}{ IP-X }} & \multirow{2}{*}{\multicolumn{2}{|c|}{ IP-Y }} & \multirow{2}{*}{\multicolumn{2}{|c|}{ Cross section }} \\
\hline & & & & & & & & \\
\hline \multicolumn{2}{|c|}{ Experiment } & & $\mathrm{l}_{\mathrm{Cl}}$ & $\mathrm{l}_{\mathrm{Cl}} / \mathrm{l}_{\mathrm{BB}}$ & $1_{\mathrm{Cl}}$ & $1_{\mathrm{Cl}} / \mathrm{l}_{\mathrm{BB}}$ & $\mathrm{V} / \mathrm{h}$ & $\mathrm{l}_{\mathrm{Cl}}(\mathrm{IP}-\mathrm{X}) * \mathrm{l}_{\mathrm{Cl}}(\mathrm{IP}-\mathrm{Y})$ \\
\hline ID & Domain & & {$[\mathrm{mm}]$} & {$[\%]$} & {$[\mathrm{mm}]$} & {$[\%]$} & {$\left[\mathrm{mm}^{2}\right]$} & {$\left[\mathrm{mm}^{2}\right]$} \\
\hline A03 & Rib & 56.9 & 2.93 & 66 & 0.73 & 100 & 0.63 & 2.14 \\
\hline A12 & Rib & 26.0 & 1.26 & 28 & 1.21 & 83 & 0.29 & 1.52 \\
\hline A13 & Rib & 136.8 & 3.59 & 81 & 1.45 & 100 & 1.52 & 5.21 \\
\hline $\mathrm{O} 2$ & Rib & 40.3 & 3.12 & 70 & 0.73 & 100 & 0.45 & 2.28 \\
\hline $\mathrm{O} 3$ & Rib & 80.5 & 4.44 & 100 & 0.73 & 100 & 0.89 & 3.24 \\
\hline $\mathrm{O} 4$ & Rib & 96.4 & 4.43 & 100 & 0.73 & 100 & 1.07 & 3.23 \\
\hline A03 & Channel & 5.2 & 0.42 & 10 & 0.46 & 63 & 0.06 & 0.19 \\
\hline A13 & Channel & 8.9 & 0.70 & 16 & 0.73 & 100 & 0.10 & 0.51 \\
\hline
\end{tabular}


Table IV. Volume-percentage and fraction of clusters of the observed water cluster connection types for rib and channel domains, as well as total cluster density for the different experimental conditions where liquid water saturation levels above $1 \%$ were found. For the channels the average value of the two channel domains is given.

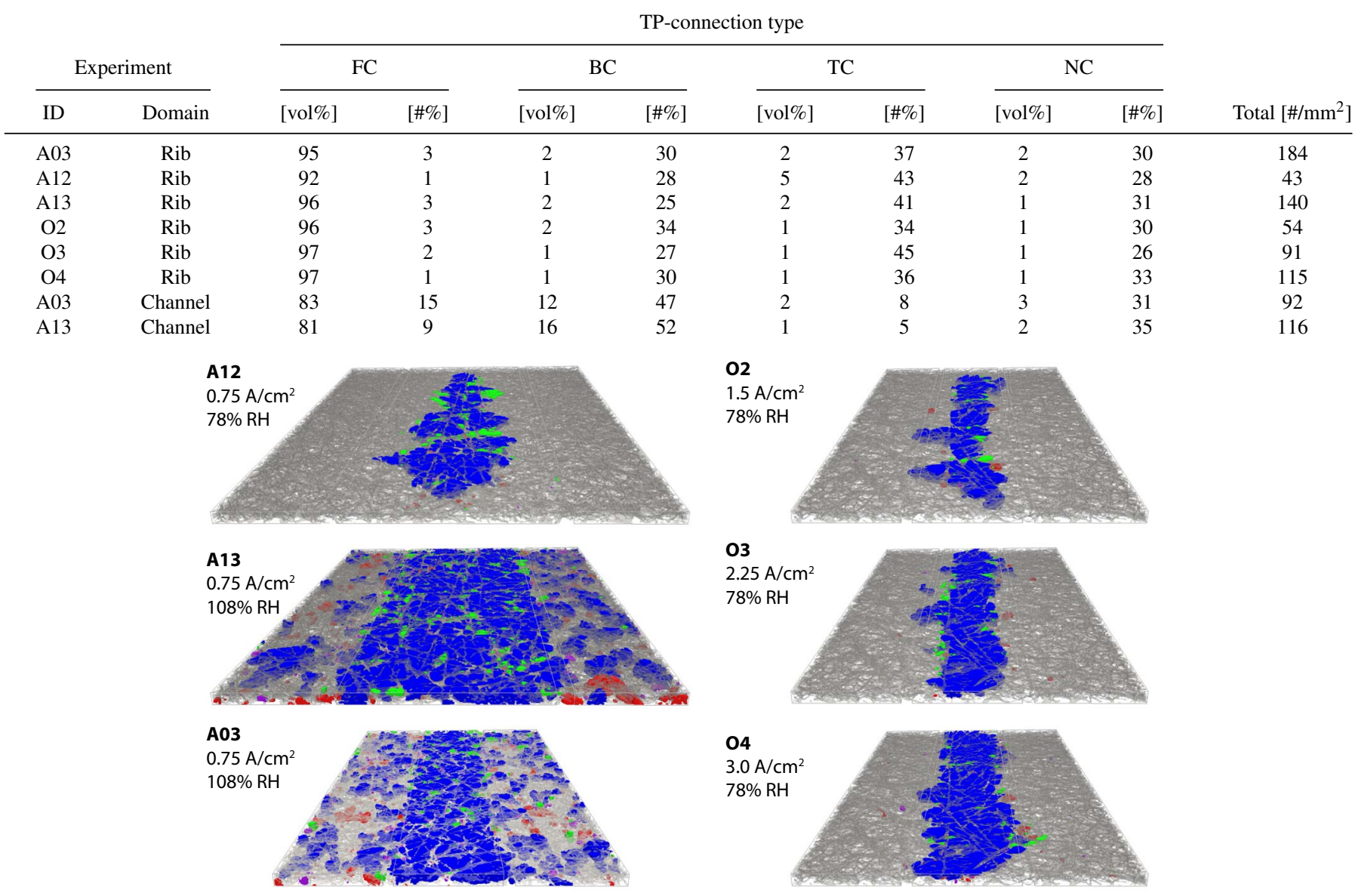

Figure 12. 3D rendering of the different cluster types for all conditions with water saturation above $1 \%$ using same color coding as in Figure 11.

The majority of the liquid water belongs to the category of FCtype clusters (see Figure 12). Under the ribs in average $96 \%$ of the water volume is fully connected in just 1 to $3 \%$ of the water clusters, independent of operating conditions or flow field width. A similarly high average FC volume fraction of $82 \%$ was found in the channel GDL domains of the oversaturated conditions A03 and A13, where about one out of ten clusters is FC connected.

$\mathrm{BC}$ and TC type water makes up 25 to $45 \%$ of the clusters under the ribs, but with negligible 1 to $5 \%$ of the liquid volume. In the channel domains however, there is a clear difference between $\mathrm{BC}$ and TC type clusters, where the majority of about $50 \%$ water clusters are of BC type occupying in average $14 \%$ of the water volume and much fewer TC type clusters (5 to $8 \%$ ) within no more than to $2 \%$ of the water volume. The volume fraction of NC type clusters is negligible under the ribs $(\sim 1 \%)$ and only slightly higher in the channel domains (3\%). Interestingly, the volume fraction of BC and FC type clusters of the channel GDL domains sums up to the FC type volume fraction under the ribs providing evidence that water transport is mainly due to capillary forces driven flow of liquid water from the MPL to the gas channel as diffusive vapor transport is negligible at oversaturated conditions. Since the available XTM scans are only temporal snapshots of the local saturation distribution, it seems possible that BC-type clusters grow into FC type or FC clusters may shrink after droplet detachment and temporarily convert into BC type.

Regarding the total cluster density, most clusters are found under the ribs of the high $\mathrm{rH}$ conditions A03 and A13. With increasing current density the cluster density increases but does not reach the values of the high humidity conditions. In the channel GDL domains 9 to $13 \# / \mathrm{mm}^{2}$ FC-type clusters were observed, which can be interpreted as the density of break-through points per area. In the rib domains, such an interpretation would be misleading, since individual clusters merge after break-through. The observed breakthrough densities are two to three times higher than the values reported recently by Hinebaugh et al. $^{45}$ for a Toray paper based GDL with MPL at similar current density of $0.6 \mathrm{~A} / \mathrm{cm}^{2}$ but lower feed gas humidity of $65 \%$.

Through-plane permeability.-After quantification, classification and localization of the TP-connected FC-category water clusters, it still remains an open question how well the liquid water is connected and how easily water can flow and drain into the gas channels. Here, the transmissibility of the water distribution in through-plane direction is quantified by the permeability of the liquid phase in the GDL, $\kappa_{l}$, that is defined only by the properties of FC-type clusters. As FC-category clusters were found only for the conditions and domains in Table IV, the analysis of liquid permeability is limited to these domains.

The calculated values for the liquid permeability $\kappa_{l}$ range between $0.7 \times 10^{-12} \mathrm{~m}^{2}(\mathrm{~A} 12)$ and $2.8 \times 10^{-12} \mathrm{~m}^{2}(\mathrm{O} 3)$ under the ribs (see Table $\mathrm{V}$ for details ${ }^{\mathrm{f}}$ ) with similar values at high current densities and at high gas feed relative humidity conditions. The slight decrease of

\footnotetext{
${ }^{\mathrm{f}} \kappa_{l}$ should not be calculated based on a segmentation of the XTM data that consider only the liquid phase as done in Eller et al ${ }^{39}$ The cluster\&island removal step incorrectly assigns parts of the non-considered solid matrix to the water phase, which leads to almost one order of magnitude too high values of $\kappa_{l}$, even though the over-estimation of the water volume is only about 10 to $15 \%$.
} 


\begin{abstract}
Table V. Cathode GDL permeabilities of dry structure $(\kappa)$, of liquid phase during operando XTM $\left(\kappa_{1}\right)$ and relative permeabilities $\left(\kappa_{\mathrm{rl}}\right)$ in TP-direction. For the channels the average value the two channel domains is given.
\end{abstract}

\begin{tabular}{ccccc}
\multicolumn{2}{c}{ Experiment } & $\kappa$ & $\kappa_{\mathbf{l}}$ & $\kappa_{\mathbf{r l}}$ \\
\cline { 1 - 3 } $\mathrm{ID}$ & Domain & {$\left[10^{-12} \mathrm{~m}^{2}\right]$} & {$\left[10^{-12} \mathrm{~m}^{2}\right]$} & {$[-]$} \\
\hline A03 & Rib & 7.9 & 2.2 & 0.28 \\
A12 & Rib & 7.6 & 0.7 & 0.09 \\
A13 & Rib & $-\|-$ & 2.7 & 0.36 \\
O2 & Rib & 9.5 & 1.9 & 0.20 \\
O3 & Rib & $-\|-$ & 2.8 & 0.29 \\
O4 & Rib & $-\|-$ & 2.6 & 0.27 \\
A03 & Channel & 8.8 & 0.7 & 0.08 \\
A13 & Channel & 7.2 & 0.6 & 0.08 \\
& & & &
\end{tabular}

liquid permeability from condition $\mathrm{O} 3$ to $\mathrm{O} 4$ might be just a temporal fluctuation of the liquid paths and shows the limitations of the low statistics for the rib domains of each condition. Still a general increase of liquid permeability with current density is observed. The liquid permeabilities $\kappa_{l}$ in the channel GDL domains are all around $0.7 \times 10^{-12} \mathrm{~m}^{2}$.

For better comparison of the rib and channel values, the liquid permeabilities have been normalized to the dry structure permeabilities, resulting in the relative liquid permeability, $\kappa_{r l}$ (see Table $\mathrm{V}$ for numerical values). It turns out that under the rib of A13 the relative liquid permeability phase is highest (0.36), while similar low values under the rib of A12 and under the channels of the oversaturated conditions A03 and A13 (0.8-0.9) are observed. The correlation of $\kappa_{r l}$ to saturation is an important parameter in PEFC models and is analyzed in Figure 13. Overall, a positive correlation between relative liquid permeabilities and saturation is observed, even though $\kappa_{r l}$ is rather stable in the channel GDL domains and slightly smaller for O4 than for O3. However the power law relationship $\kappa_{r l}=s^{3}$ that is commonly used in PEFC modeling (e.g. Wang and Wang, ${ }^{46}$ Flückiger, ${ }^{47}$ Litster and Djilali ${ }^{21}$ ) appears to be conservative on the low end for the relative liquid permeability. An exponent between 1.5 and 2 seems a more appropriate match for the present data.

The reader should keep in mind, that the through-plane values of $\kappa_{r l}$ under the ribs do not provide a complete picture regarding the draining capabilities of the liquid saturation toward the channels, since the liquid water needs to flow in in-plane direction under the ribs to reach the flow channels. Consequently, the analysis domain has been enlarged in in-plane direction such that the domain of a channel-ribchannel repetition-unit is covered, which includes the required inplane transport from the rib toward the channel domains. The domain

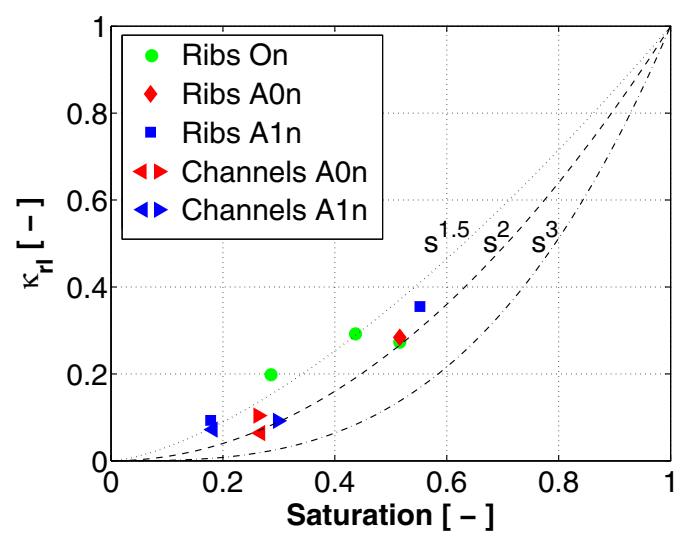

Figure 13. Through-plane relative liquid $\kappa_{r l}$ permeabilities for rib and channel domains of conditions with GDL saturation different than zero; triangle symbols point toward left or right for individual channel domains; dashed lines are $\kappa_{r l}=s^{x}$, with $x=1.5,2,3$.
Table VI. Liquid permeabilities and pressure drop of the cathode
GDL channel-rib repetition cells. The pressure drop is calculated for the specific current density of each condition.

\begin{tabular}{|c|c|c|c|}
\hline \multicolumn{2}{|c|}{ Experiment } & \multirow{2}{*}{$\begin{array}{c}\mathrm{\kappa}_{\mathrm{l}} \\
{\left[10^{-12} \mathrm{~m}^{2}\right]}\end{array}$} & \multirow{2}{*}{$\begin{array}{c}\text { Pressure Drop } \\
{[\mathrm{Pa}]}\end{array}$} \\
\hline ID & Domain & & \\
\hline A03 & Repetition Unit & 0.53 & 0.05 \\
\hline A 12 & Repetition Unit & - & - \\
\hline A13 & Repetition Unit & 0.23 & 0.11 \\
\hline $\mathrm{O} 2$ & Repetition Unit & 0.03 & 1.77 \\
\hline O3 & Repetition Unit & 0.06 & 1.36 \\
\hline $\mathrm{O} 4$ & Repetition Unit & 0.02 & 5.04 \\
\hline
\end{tabular}

is further enlarged by a layer of one voxel in TP-direction on top. This additional layer is set permeable for liquid in the channel area (porosity $=100 \%$, saturation $=100 \%$ ) and impermeable in the rib area (porosity $=0 \%$, saturation $=0 \%$ ).

The calculated values of $\kappa_{l}$ for the repetition unit domains are smaller than for the isolated GDL domains (see Table VI). For the high $\mathrm{rH}$ conditions, the values are slightly below those of their channel domains, ranging between $0.2 \times 10^{-12} \mathrm{~m}^{2}$ (A13) and $0.5 \times 10^{-12} \mathrm{~m}^{2}$ (A03) due to the impermeable coverage of the rib domains. In case of the current density variations, the channel GDL domains don't contribute to liquid transport and the values are even one order of magnitude smaller, between $0.02 \times 10^{-12} \mathrm{~m}^{2}(\mathrm{O} 4)$ and $0.06 \times 10^{-12} \mathrm{~m}^{2}$ (O3).

If it is assumed that all water transport occurs in liquid phase, the repetition unit cell TP-liquid permeabilities can be used to derive upper limits of the pressure drop that is present in the FC-connected water clusters as shown in Table VI. In case of O4, where the lowest TP liquid permeability of the repetition unit domains was identified and the highest pressure drop can be expected, the pressure drop for a liquid water flow rate equivalent to a current density of $3 \mathrm{~A} / \mathrm{cm}^{2}$ is just about $5 \mathrm{~Pa}$. Such low pressure drops are three orders of magnitude away from breakthrough pressure ${ }^{22,27,44}$ or pressures that are required for in-plane growth after breakthrough under a rib-structure for Toraytype GDL. ${ }^{44}$

Santamaria et al. ${ }^{22}$ reported similar post-break-through liquid permeabilities of $0.5 \times 10^{-12} \mathrm{~m}^{2}$ for Toray TGP-H-030 and TGP-H-060 papers with $5 \mathrm{wt} \%$ PTFE that were obtained from liquid water imbibition experiments. At flow rates that correspond to a capillary number of $\log C a=-4$ at the injection point at the bottom of the GDL, they measured post break-through pressure drops of about $1 \mathrm{kPa}(10 \mathrm{mbar})$ for both GDL types. A current density of $1 \mathrm{~A} / \mathrm{cm}^{2}$ corresponds to a much smaller capillary number of $\log C a=-8.4$ and therefore far lower fluid velocity, which explains the about 3 orders of magnitude smaller pressure drops in the numerical evaluation of this work. Hence, the calculated pressure drops of this study comply well with the experimental values reported in Ref. 22.

\section{Discussion}

Regarding the reported cluster volumes the reader should keep in mind, that they are restricted by the experimental and imaging conditions. The along-the-channel dimension of the catalyst layer domain limits the size of the largest clusters at least for the high current density conditions $\mathrm{O} 3$ and $\mathrm{O} 4$, since they expand over the entire length of catalyst layer domain in gas flow direction. It can be expected that the liquid water forms a continuous path and thus much larger clusters over a significant length of the ribs in a larger technical cell for similar conditions. The same argument holds in TP direction for FC type clusters at all conditions, as their size will scale with the thickness of analyzed GDL domain. Depending on the specific position of the analyzed domain, this is also true for BC and TC clusters. An average in-plane coverage of the individual FC-type clusters might therefore be a more easily transferable number to compare with other materials and conditions. It turns out that such a measure is underestimating 
the dimensions of the in-plane area of the cluster bounding box by a factor of 3 to 5 as shown in Table III for the largest water cluster of each domain. The larger FC-type clusters that are observed in the channel domains of the oversaturated conditions (volumes of 1-10 nL) have consequently an IP-size over 0.03 to $0.5 \mathrm{~mm}^{2}$, while the larger clusters under the ribs $(\sim 100 \mathrm{~nL})$ span over about 3 to $5 \mathrm{~mm}^{2}$.

The observed expansion of the FC type water clusters in the channel GDL domains sets some boundaries for the dimensioning of recent efforts to separate the transport paths of the liquid water and the gases in the GDL by means of patterned wettability. ${ }^{48-50}$ It would require hydrophilic domain about every $200 \mu \mathrm{m}$ such that they could connect to every FC type cluster of $1 \mathrm{~nL}$ size, or even every $100 \mu \mathrm{m}$ for the smallest observed FC clusters in the channel domain of only $0.2 \mathrm{~nL}$, as postulated already in Ref. 48. Even though the patterning of the GDL surface is possible down to $100 \mu \mathrm{m}$, the resulting water structures exhibit a feature width of $250 \mu \mathrm{m} .{ }^{50}$ It remains therefore unclear if it will be possible to collect the water of all FC-type clusters with such structures in the GDL channel domains. The reported wettability patterns used for cell testing had $500 \mu \mathrm{m}$ wide hydrophilic lines with a pitch of $950 \mu \mathrm{m}^{48}$ implemented on Toray TGP-H-060 that were oriented perpendicular to the channel and rib structures. They showed a beneficial cell performance at higher current densities, even though the hydrophilic lines could not influence the FC water clusters over one millimeter wide domains in the channel. It is therefore likely that at least part of the cell performance improvements stems from modified water drainage and reduced saturation under the ribs, where the FC clusters form a slim stripe at the center of the ribs before they grow in-plane toward the channels in the unpatterned GDL of this study.

The observed liquid saturation and the calculated liquid permeabilities are by far sufficient to drain the liquid product water of present and upcoming current densities without significant pressure drops into the gas channels. This allows to draw two conclusions. First, it means that the channel-connected FC-type clusters can't grow further by capillary pressure driven processes as the pressure to overcome the pore throat barrier can't be reached. They can only increase in volume if growing $\mathrm{BC}, \mathrm{TC}$, or NC-type water clusters merge with the channel connected FC-type cluster.

Second, one could imagine, that the reduction of the liquid permeability by two or three orders would still result in pressure drops smaller than the breakthrough pressure for Toray TGP-H-060 at a current density of $10 \mathrm{~A} / \mathrm{cm}^{2}$. The challenging question is how to reduce the saturation in the GDL at (over-)saturated gases in the channel domains. Presently, the random in-plane fiber positioning of Toray type GDLs makes it likely that a large in-plane pore is crossed by other carbon fibers at a near distance in the through-plane direction, such that the sphere-based pore diameter is limited by the throughplane (circular) throat cross-section diameter. This leads furthermore to rather tortuous vertically oriented percolation paths with a large difference of the maximum to minimum in-plane pore cross sections. Different approaches to create non-tortuous through-plane transport paths such as holes or grooves in the GDL have been reported. ${ }^{51-54}$ Alternatively, a more regular in-plane pattern of the fibers that is repeated in through-plane direction could reduce the TP-constriction and tortuosity. For both approaches the sphere-based pore diameter would be limited by the in-plane circular cross-section of the pores. Close to the GDL-rib interface the (structured) GDL should additionally provide a fiber arrangement that facilitates in-plane transport of the liquid water toward the channels. Altogether this would lead to lower breakthrough pressures and stronger vertical expansion of the water clusters, which finally could reduce GDL saturation.

\section{Summary}

$\mathrm{X}$-ray tomographic microscopy has been applied to quantify saturation, cluster sizes, connectivity as well as the permeability of the liquid water in the cathode GDL of PEFCs with two different rib widths and operated in differential mode at various current densities and feed gas humidities at $80^{\circ} \mathrm{C}$ cell temperature. The quantification of the liquid saturation was limited to the top $90 \mu \mathrm{m}$ of the cathode GDL as artifacts of the strong absorbing catalyst layer prevented serious solid segmentation of the GDL/MPL closer to the catalyst layer. The analyzed GDL domain still represents about two thirds of the compressed MPL-free GDL substrate.

At the optimal feed gas humidification level of $78 \% \mathrm{rH}$ for operation at a current density of $0.75 \mathrm{~A} / \mathrm{cm}^{2}$ no liquid water was detected in the rib area of the cathode GDL for the narrow rib, but a saturation of $16 \%$ was seen for the wider rib width. At $108 \%$ feed gas relative humidity, a cell voltage drop of about $70 \mathrm{mV}$ was observed at a cathode GDL saturation of about 25\% (channels) to 55\% (ribs). During operation with $\mathrm{H}_{2} / \mathrm{O}_{2}$ the saturation increased with current density, reaching average values of up to $52 \%$ under the rib at $3.0 \mathrm{~A} / \mathrm{cm}^{2}$ and $78 \% \mathrm{rH}$ feed gas humidity. Different patterns of the saturation under the ribs were observed. While the saturation was found homogeneously distributed at the oversaturated conditions, it was centered under the ribs in case of high current density conditions.

The density of water clusters under the ribs scaled with saturation for variations of feed gas humidity as well as for increasing current density with the highest values found at oversaturated conditions. Under the channels the water clusters can drain directly into the channel and do not grow above $10 \mathrm{~nL}$ as they remain isolated, whereas water clusters with volumes of up to $130 \mathrm{~nL}$ are found under the ribs. Here, the GDL-rib interface seems to act as a barrier that forces the TP-transport clusters to join - may it be due to capillary forces driven in-plane growth or condensation under the ribs.

The classification of the water cluster connectivity in the GDL revealed that in average $85 \%$ (channel) to $95 \%$ (rib) of the liquid water volume is fully connected in TP direction and contributes to liquid water transport from the catalyst layer to the flow field with no more then $3 \%$ (rib) to $15 \%$ (channel) of the water clusters. In the channel domains this corresponds to about 10 to 14 breakthrough points per $\mathrm{mm}^{2}$. While other connectivity types are negligible in terms of volumetric share under the ribs, a significant amount of water (up to $15 \%$ ) that is connected only toward the MPL/CL has been found in the channel GDL domains at oversaturated conditions.

The dependency of the calculated liquid permeabilities on the observed saturation can be described with a power law using an exponent between 1.5 and 2 for all channel and rib GDL domains. Modeling studies using higher exponents of 3 or higher are likely to underestimate the liquid permeability at low saturations.

Based on numerical simulations on channel-rib repetition unit domains it can be concluded that the pressure drop due to liquid flow between the catalyst layer and the gas channels in fully TP-connected water clusters is not higher than $5 \mathrm{~Pa}$ for the present data. Such water clusters can't grow further by capillary forces since the required pressures for capillary driven growth for Toray paper GDLs are about 3 orders of magnitude higher. Only disconnected water clusters that grow toward and finally merge with the larger fully TP-connected clusters can lead to cluster size growth.

To identify temporal fluctuations of the water clusters, to visualize break-through, horizontal growth and merge of the liquid domains under the ribs, or the origin of the different cluster connection types a higher temporal resolution is required for the XTM method. Efforts to process XTM data with lower signal to noise characteristics that is required to decrease the scan times are ongoing ${ }^{55}$.

\section{Acknowledgment}

Financial support from the Swiss Federal Office of Energy under grant no. 153708 , precise machining work by M. Hottiger, software and electronic support by T. Gloor, and support during measuring campaign at the TOMCAT beamline by S. Irvine, R. Gaudenzi, S. Kreitmeier and M. Zurbrügg are gratefully acknowledged.

\section{References}

1. Ene-farm installed 120,000 residential fuel cell units, 2015. https://fuelcellsworks. com/archives/2015/09/23/ene-farm-installed-120000-residentialfuel-cell-units/ Accessed 20th July 2016. 
2. N. Konno, S. Mizuno, H. Nakaji, and Y. Ishikawa, Development of compact and high-performance fuel cell stack, SAE Int. J. Alt. Power, 4(1), 123 (2015).

3. Hyundai ix35 fuel cell, 2013. http://www.hyundainews.com/us/en/media/pressreleases/ 38232 Accessed 20th July 2016.

4. M. Felgenhauer and T. Hamacher, State-of-the-art of commercial electrolyzers and on-site hydrogen generation for logistic vehicles in south carolina, Int. J. Hydrogen Energy, 40(5), 2084 (2015).

5. O. Gröger, H. A. Gasteiger, and J.-P. Suchsland, Review-Electromobility: Batteries or Fuel Cells?, J. Electrochem. Soc., 162(14), A2605 (2015).

6. T. A. Zawodzinski, C. Derouin, S. Radzinski, R. J. Sherman, V. T. Smith, T. E. Springer, S. Gottesfeld, Water Uptake by and Transport Through Nafion $117 \mathrm{Mem}-$ branes, J. Electrochem. Soc., 140(4), 1041 (1993).

7. M. F. Mathias, J. Roth, J. Fleming, and W. Lehnert, Diffusion media materials and characterisation. In Handbook of Fuel Cells. John Wiley \& Sons, Ltd, 2010.

8. D. R. Baker, C. Wieser, K. C. Neyerlin, and M. W. Murphy, The Use of Limiting Current to Determine Transport Resistance in PEM Fuel Cells, ECS Trans., 3(1), 989 (2006).

9. P. Boillat, P. Oberholzer, A. Kaestner, R. Siegrist, E. H. Lehmann, G. G. Scherer, and A. Wokaun, Impact of water on PEFC performance evaluated by neutron imaging combined with pulsed helox operation, J. Electrochem. Soc., 159(7), F210 (2012).

10. P. Oberholzer, P. Boillat, A. Kaestner, E. H. Lehmann, G. G. Scherer, T. J. Schmidt, and A. Wokaun, Characterizing local o2 diffusive losses in GDLs of PEFCs using simplified flow field patterns ("2D”, "1D", “0D”) J. Electrochem. Soc., 160(6), F659 (2013).

11. R. Mukundan, J. R. Davey, T. Rockward, J. S. Spendelow, B. Pivovar, D. S. Hussey, D. L. Jacobson, M. Arif, and R. Borup, Imaging of water profiles in pem fuel cells using neutron radiography: Effect of operating conditions and gdl composition, ECS Trans., 11(1), 411 (2007).

12. P. Boillat, D. Kramer, B. C. Seyfang, G. Frei, E. Lehmann, G. G. Scherer, A. Wokaun, Y. Ichikawa, Y. Tasaki, and K. Shinohara, In situ observation of the water distribution across a PEFC using high resolution neutron radiography, Electrochem. Commun., 10(4), 546 (2008)

13. P. Oberholzer and P. Boillat, Local characterization of PEFCs by differential cells Systematic variations of current and asymmetric relative humidity, J. Electrochem. Soc., 161(1), F139 (2014).

14. U. Pasaogullari and C.-Y. Wang, Two-Phase Modeling and Flooding Prediction of Polymer Electrolyte Fuel Cells, J. Electrochem. Soc., 152(2), A380 (2005).

15. P. K. Sinha, P. P. Mukherjee, and C.-Y. Wang, Impact of GDL structure and wettability on water management in polymer electrolyte fuel cells, J. Mater. Chem., 17, 3089 (2007).

16. T. Koido, T. Furusawa, and K. Moriyama, An approach to modeling two-phase transport in the gas diffusion layer of a proton exchange membrane fuel cell, J. Power Sources, 175(1), 127 (2008).

17. P. P. Mukherjee, C.-Y. Wang, and Q. Kang, Mesoscopic modeling of two-phase behavior and flooding phenomena in polymer electrolyte fuel cells, Electrochim. Acta, 54(27), 6861 (2009).

18. M. Leverett, Capillary behavior in porous solids, Trans. AIME, 142, 152 (1941).

19. M. Th. van Genuchten, A Closed-form Equation for Predicting the Hydraulic Conductivity of Unsaturated Soils, Soil Sci. Soc. Am. J., 44, 892 (1980).

20. Manolis M. Tomadakis and Stratis V. Sotirchos, Ordinary and transition regime diffusion in random fiber structures, AIChE Journal, 39(3), 397 (1993).

21. N. Litster and N. Djilali, Two-phase transport in porous gas diffusion electrodes. In M. Faghri and B. Sundén, editors, Transport Phenomena in Fuel Cells, pages 175-214, Southhampton, UK, 2005. WIT Press.

22. A. D. Santamaria, P. K. Das, J. C. MacDonald, and A. Z. Weber, Liquid-water interactions with gas-diffusion-layer surfaces, J. Electrochem. Soc., 161(12), F1184 (2014)

23. M. Reum, S. A. Freunberger, A. Wokaun, and F. N. Büchi, Measuring the Current Distribution with Sub-Millimeter Resolution in PEFCs, J. Electrochem. Soc., 156(3), B301 (2009).

24. P. Deevanhxay, T. Sasabe, S. Tsushima, and S. Hirai, Observation of dynamic liquid water transport in the microporous layer and gas diffusion layer of an operating PEM fuel cell by high-resolution soft X-ray radiography, J. Power Sources, 230, 38 (2013)

25. A. Schneider, C. Wieser, J. Roth, and L. Helfen, Impact of synchrotron radiation on fuel cell operation in imaging experiments, J. Power Sources, 195(19), 6349 (2010).

26. K. Moriyama, T. Tachihara, and T. Furusawa, Development of in-situ X-ray imaging technologies for measuring water distribution in generating PEFC, Honda $R \& D$ Technical Review, 23, 50 (2011).

27. R. Flückiger, F. Marone, M. Stampanoni, A. Wokaun, and F. N. Büchi, Investigation of liquid water in gas diffusion layers of polymer electrolyte fuel cells using X-ray tomographic microscopy, Electrochim. Acta, 56(5), 2254 (2011).

28. J. Eller, Tomas Rosén, F. Marone, M. Stampanoni, A. Wokaun, and F. N. Büchi, Progress in In Situ X-Ray Tomographic Microscopy of Liquid Water in Gas Diffusion Layers of PEFC, J. Electrochem. Soc., 158(8), B963 (2011).
29. Ph. Krüger, H. Markötter, J. Haussmann, M. Klages, T. Arlt, J. Banhart, C. Hartnig, I. Manke, and J. Scholta, Synchrotron X-ray tomography for investigations of water distribution in polymer electrolyte membrane fuel cells, J. Power Sources, 196(12), 5250 (2011).

30. M. Maeda, Y. Isogai, M. Shiozawa, T. Tejima, and J. Hamada, Analysis of water distribution in a fuel cell using X-ray computed tomography, Denso Technical Review, 13, 37 (2008)

31. J. Eller, J. Roth, F. Marone, M. Stampanoni, A. Wokaun, and F. N. Büchi, Towards Ultra-Fast X-ray Tomographic Microscopy of Liquid Water in PEFC, ECS Trans., 41(1), 387 (2011).

32. T. Rosén, J. Eller, J. Kang, N. I. Prasianakis, J. Mantzaras, and F. N. Büchi, Saturation Dependent Effective Transport Properties of PEFC Gas Diffusion Layers, $J$. Electrochem. Soc., 159(9), F536 (2012).

33. I. Mayrhuber, F. Marone, M. Stampanoni, T. J. Schmidt, and F. N. Büchi, Fast Xray tomographic microscopy: Investigating mechanisms of performance drop during freeze starts of polymer electrolyte fuel cells, ChemElectroChem, 2(10), 1551 (2015).

34. J. Roth, J. Eller, F. N. Büchi, Effects of Synchrotron Radiation on Fuel Cell Materials, J. Electrochem. Soc., 159(8), F449 (2012).

35. J. Eller and F. N. Büchi, Polymer electrolyte fuel cell performance degradation at different synchrotron beam intensities, J. Synchrotron Radiat., 21(1), 82 (2014).

36. M. Stampanoni, A. Groso, A. Isenegger, G. Mikuljan, Q. Chen, A. Bertrand, S. Henein, R. Betemps, U. Frommherz, P. Böhler, D. Meister, M. Lange, and R. Abela, Trends in synchrotron-based tomographic imaging: the SLS experience, Proc. SPIE 6318, 63180M (2006).

37. R. Mokso, F. Marone, D. Haberthur, J. C. Schittny, G. Mikuljan, A. Isenegger, and M. Stampanoni, Following Dynamic Processes by X-ray Tomographic Microscopy with Sub-second Temporal Resolution, AIP Conf. Proc., 1365(1), 38 (2011).

38. D. Sage, Local Normalization. EPFL, Lausanne, Switzerland, 2002.

39. J. Eller, J. Roth, R. Gaudenzi, S. Irvine, F. Marone, M. Stampanoni, A. Wokaun, and F. N. Büchi, Water Distribution in GDL near Optimal Humidification, ECS Trans., 50(2), 477 (2013).

40. J. Eller, X-ray Tomographic Microscopy of Polymer Electrolyte Fuel Cells. $\mathrm{PhD}$ thesis, Nr. 20916, ETH Zurich, 2012

41. J. Roth, J. Eller, F. Marone, and F. N. Büchi, Investigation of the representative area of the water saturation in gas diffusion layers of polymer electrolyte fuel cells, $J$. Phys. Chem. C, 117(49), 25991 (2013).

42. The MathWorks Inc., Natick, MA. 1984-2012.

43. R. Flückiger, S. A. Freunberger, D. Kramer, A. Wokaun, G. G. Scherer, and F. N. Büchi, Anisotropic, effective diffusivity of porous gas diffusion layer materials for PEFC, Electrochim. Acta, 54(2), 551 (2008).

44. A. Lamibrac, J. Roth, M. Toulec, F. Marone, M. Stampanoni, and F. N. Büchi, Characterization of liquid water saturation in gas diffusion layers by X-ray tomographic microscopy, J. Electrochem. Soc., 163(3), F202 (2016).

45. J. Hinebaugh, J. Lee, C. Mascarenhas, and A. Bazylak, Quantifying percolation events in PEM fuel cell using synchrotron radiography, Electrochim. Acta, 184, 417 (2015).

46. Y. Wang and C.-Y. Wang, A Nonisothermal, Two-Phase Model for Polymer Electrolyte Fuel Cells, J. Electrochem. Soc., 153(6), A1193 (2006).

47. R. Flückiger, Transport Phenomena on the Channel-Rib Scale of Polymer Electrolyte Fuel Cells. PhD thesis, Nr. 18509, ETH Zurich, 2009.

48. A. Forner-Cuenca, J. Biesdorf, L. Gubler, P. M. Kristiansen, T. J. Schmidt, and P. Boillat, Engineered water highways in fuel cells: Radiation grafting of gas diffusion layers, Adv. Mater, 27(41), 6317 (2015)

49. A. Forner-Cuenca, V. Manzi-Orezzoli, J. Biesdorf, M. El Kazzi, D. Streich, L. Gubler, T. J. Schmidt, and P. Boillat, Advanced water management in PEFCs: Diffusion layers with patterned wettability: I. synthetic routes, wettability tuning and thermal stability, J. Electrochem. Soc., 163(8), F788 (2016).

50. A. Forner-Cuenca, J. Biesdorf, A. Lamibrac, V. Manzi-Orezzoli, F. N. Büchi, L. Gubler, T. J. Schmidt, and P. Boillat, Advanced water management in PEFCs: Diffusion layers with patterned wettability: Ii. measurement of capillary pressure characteristic with neutron and synchrotron imaging, J. Electrochem. Soc., 163(9), F1038 (2016).

51. D. P Wilkinson and J. St-Pierre, In-plane gradients in fuel cell structure and conditions for higher performance, J. Power Sources, 113(1), 101 (2003).

52. D. Gerteisen, T. Heilmann, and C. Ziegler, Enhancing liquid water transport by laser perforation of a GDL in a PEM fuel cell, J. Power Sources, 177(2), 348 (2008).

53. K. Nishida, T. Murakami, S. Tsushima, and S. Hirai, Measurement of liquid water content in cathode gas diffusion electrode of polymer electrolyte fuel cell, J. Power Sources, 195(11), 3365 (2010).

54. R. Alink, J. Haussmann, H. Markötter, M. Schwager, I. Manke, and D. Gerteisen, The influence of porous transport layer modifications on the water management in polymer electrolyte membrane fuel cells, J. Power Sources, 233(0), 358 (2013).

55. J. Eller, F. Marone, and F. N. Büchi, Operando sub-second tomographic imaging of water in pefc gas diffusion layers, ECS Trans., 69(17), 523 (2015). 